\title{
Desarrollo larval de Palaemonetes mexicanus y P. hobbsi (Caridea: Palaemonidae) cultivadas en el laboratorio
}

\section{Larval development of Palaemonetes mexicanus and P. hobbsi (Caridea: Palaemonidae) reared in the laboratory}

\author{
Gabino A. Rodríguez-Almaráz*, Rodolfo Muñiz-Martínez y Alejandro Millán-Cervantes \\ Facultad de Ciencias Biológicas, Universidad Autónoma de Nuevo León. Av. Pedro de Alba s/n, Ciudad Universitaria, 66450 San Nicolás de los \\ Garza, Nuevo León, México. \\ *Correspondencia: balanus2006@yahoo.com.mx
}

\begin{abstract}
Resumen. Los langostinos del género Palaemonetes ocupan una amplia variedad de hábitats, desde condiciones marinas hasta agua dulce. El desarrollo larval de las especies marinas o salobres es prolongado, mientras que el de las especies de agua dulce es breve. En este estudio se compararon aspectos reproductivos y del desarrollo larval de $P$. mexicanus y $P$. hobbsi, especies residentes en cuerpos de agua dulce del noreste de México. Las hembras grávidas de cada especie fueron recolectadas en la localidad tipo y mantenidas en el laboratorio a temperaturas de 22 a $24^{\circ} \mathrm{C}$. Las larvas recién eclosionadas obtenidas de estas hembras fueron cultivadas individualmente bajo las mismas condiciones de temperatura y suministrando como alimento larvas de Artemia recién eclosionadas y hojuelas para peces. Tanto P. mexicanus como P. hobbsi, tienen 3 estadios larvales y 2 etapas postlarvales. El tiempo de desarrollo promedio desde zoea I hasta la postlarva II fue de 12 días en $P$. hobbsi y 16 días en P. mexicanus. La morfología larval de ambas especies es casi idéntica. Sin embargo, existen caracteres morfológicos de cada estadio larval que permiten diferenciar las especies. Se discuten aspectos de fecundidad, biometría de hembras, huevecillos y larvas.
\end{abstract}

Palabras clave: Caridea, Palaemonetes, desarrollo larval, noreste de México.

\begin{abstract}
The caridean genus Palaemonetes occupies a wide variety of habitats from marine conditions to fresh-water. The marine and brackish species have an extended larval development, while fresh-water species have an abbreviated larval cycle. In this study reproductive aspects and type of larval development were compared between P. mexicanus and $P$. hobbsi, both fresh-water species from northeast Mexico. Ovigerous females of each species were collected at the type locality and maintained in the laboratory at temperatures between 22 a $24^{\circ} \mathrm{C}$. The larvae were reared individually at the same temperature conditions, and newly hatched nauplii of Artemia and fish flakes were provided as food. P. mexicanus and $P$. hobbsi have an abbreviated development consisting of 3 larval and 2 postlarval stages. The larval cycle including the postlarva had a duration of 12 days for $P$. hobbsi, while in P. mexicanus lasted 16 days. The larval development of both species is almost identical. However, there are morphological features that can differentiate both species. Aspects of fecundity, biometry of females, eggs and larvae are discussed.
\end{abstract}

Key words: Caridea, Palaemonetes, larval development, northeast Mexico.

\section{Introducción}

Los langostinos palémonidos del género Palaemonetes ocupan una amplia variedad de hábitats desde condiciones marinas hasta ambientes de agua dulce (Dobkin, 1971; Strenth, 1976; Guerao, 1993). En Norteamérica, incluyendo México, se conocen 9 especies de agua dulce de Palaemonetes (Strenth, 1976; Strenth et al., 1988), y sólo para P. kadiakensis (Broad y Hubschman, 1963), $P$. paludosus (Dobkin, 1963), P. cummingi (Dobkin, 1971) y

Recibido: 27 abril 2010; aceptado: 03 junio 2010
$P$. antrorum (Strenth et al., 1988) se ha estudiado el ciclo larval en laboratorio. Estas especies, a excepción de $P$. kadiakensis, tienen un desarrollo abreviado que incluye 3 estadios de zoea y 1 o 2 fases postlarvales (Dobkin, 1963, 1971; Strenth et al., 1988; Strenth, 1991; Guerao, 1993). La reducción del ciclo larval de algunas especies de Palaemonetes y Macrobrachium ha permitido que se adapten y colonicen los ambientes de agua dulce (Álvarez et al., 2002). El presente estudio fue hecho en el laboratorio, con el propósito de contribuir con aspectos reproductivos y del desarrollo larval de P. mexicanus (Strenth, 1976) y $P$. hobbsi (Strenth, 1994), especies morfológicamente 
similares, que coexisten en sistemas hidrológicos del noreste de México. Palaemonetes mexicanus fue previamente descrita y conocida de un arroyo a $24 \mathrm{~km}$ al oeste de Ciudad Valles, San Luis Potosí; posteriormente, Rodríguez-Almaraz y Muñiz-Martínez (2008) ampliaron la distribución de esta especie. Por otra parte, P. hobbsi es residente de ríos cercanos a Ciudad Mante, Tamaulipas (Strenth, 1994; Rodríguez-Almaraz y Muñiz-Martínez, 2008).

\section{Materiales y métodos}

Se recolectaron lotes de hembras grávidas de $P$. hobbsi y $P$. mexicanus en sus respectivas localidades tipo: río El Nacimiento, Ciudad Mante, Tamaulipas, México $\left(22^{\circ} 43^{\prime} 06.66^{\prime \prime} \mathrm{N}, 98^{\circ} 59^{\prime} 11.22^{\prime \prime} \mathrm{O}\right)$ para $P$. hobbsi, y río Nacimiento, $24 \mathrm{~km}$ al oeste de Ciudad Valles, San Luis Potosí, México $\left(21^{\circ} 58^{\prime} 30.36^{\prime \prime}\right.$ N, 99¹1²8.08“ O) para P. mexicanus. Para la recolección se utilizaron redes tipo cuchara (abertura de malla de $4 \mathrm{~mm}$ ), que se introdujeron entre la vegetación riparia y sumergida en las áreas someras de ambas localidades. Los muestreos se realizaron en junio de 2004, marzo de 2005 y mayo y octubre de 2006.

Los ejemplares fueron transportados al laboratorio en cajas de plástico que contenían plantas acuáticas del sitio de recolección y que sirvieron como sustrato y refugio para los langostinos. A los recipientes de traslado se agregó hielo para mantener la temperatura del agua entre 22 y $24^{\circ} \mathrm{C}$, a fin de reducir la actividad de las hembras y evitar su mortalidad o la de los huevecillos.

En el laboratorio, las hembras grávidas se depositaron en recipientes individuales de vidrio $(600 \mathrm{ml})$ con agua desclorada y renovada diariamente para eliminar restos del alimento (hojuelas Tetra Min para peces ) y así evitar la contaminación de los huevecillos por hongos. Para estimar la fecundidad, se contabilizó el número de huevecillos que portaba otro lote de hembras, se midió la longitud del cefalotórax (LC) de las hembras, así como el ancho y largo de los huevecillos. Los recipientes se monitorearon 2 veces por día con el fin de observar la sobrevivencia de las hembras y la presencia de larvas recién eclosionadas que inmediatamente fueron separadas en recipientes individuales del mismo tipo y se mantuvieron bajo las mismas condiciones de cultivo.

El seguimiento del desarrollo larval se realizó mediante la observación de mudas de 30 organismos (zoea I) de cada especie, con un monitoreo de 3 veces al día. De esta manera se determinó la duración (días) de cada estadio larval. Las larvas fueron alimentadas con larvas recién eclosionadas de Artemia y hojuelas para peces; sin embargo, las larvas no aceptaron el alimento vivo, sólo el alimento artificial.
De cada estadio larval y postlarval (zoea I-III - postlarva I-II) se seleccionaron entre 2 y 10 organismos de cada especie para la medición de la longitud total (LT) y posteriormente se fijaron en etanol al $70 \%$. Antes de la disección, las larvas fueron teñidas con verde de metilo al $1 \%$ durante $8 \mathrm{~h}$ y en seguida enjuagadas en etanol. Las partes corporales o de apéndices se introdujeron en una solución de etanol al $70 \%$ y glicerina, en portaobjetos excavados. Se midieron y dibujaron las piezas utilizando un microscopio estereoscopio Olympus SZX12 y un microscopio Carl Zeiss Axiostar adaptados con cámara clara. Los dibujos fueron digitalizados y editados en el programa Adobe Ilustrador Artwork 13.

\section{Descripciones}

La LC promedio de las hembras grávidas de $P$. mexicanus fue $11.1 \mathrm{~mm}$, con talla mínima de 8.7 y máxima de $12.4 \mathrm{~mm}$. En el caso de P. hobbsi, la talla promedio fue $10.8 \mathrm{~mm}$, con un intervalo de 9.1 a $12.2 \mathrm{~mm}$. Ambos promedios no presentaron diferencias significativas $(t=$ 1.26; $\mathrm{p}>0.05$ ). El número de huevecillos adheridos en las hembras de $P$. mexicanus osciló de 5 a 17, mientras que en P. hobbsi fue de18 a 31. En ambas especies los huevecillos fueron de forma ovalada y aspecto granuloso total o parcial, de color verde brillante. La talla mínima y máxima de los huevecillos de P. mexicanus ( $\mathrm{n}=40)$ (largo $\times$ ancho) fue 1.10 $\times 0.70 \mathrm{~mm}$ y $1.80 \times 1.40 \mathrm{~mm}$, y de $P$. hobbsi $(\mathrm{n}=45), 0.90$ $\times 0.80 \mathrm{~mm}$ y $1.60 \times 1.10 \mathrm{~mm}$. El tiempo para la eclosión de huevecillos fue de 2 a 7 días, una vez que las hembras fueron confinadas en el laboratorio, desconociéndose el tiempo de incubación previo a la recolección de las hembras. Durante la incubación las hembras presentaron "un cuidado maternal" que consistió en movimientos rítmicos de los pleópodos y una vez que los huevecillos iniciaron la eclosión, las hembras permanecieron inmóviles en el fondo del recipiente, con sus pereiópodos erguidos y plegando el abdomen; posteriormente realizaron movimientos lentos, probablemente con el fin de liberar de 2 a 3 larvas recién eclosionadas. La primera zoea de ambas especies fue de poca actividad; las larvas permanecieron inmóviles y sin alimentarse. En etapas larvales posteriores, las larvas fueron más activas en movimiento y se alimentaron con trozos del alimento artificial. En la descripción de cada estadio larval y postlarval se incluye el valor promedio y el intervalo de longitud total.

El tiempo de duración de cada estadio larval y postlarval fue muy similar en ambas especies, excepto la postlarva II que en $P$. hobbsi fue de 1 día y en $P$. mexicanus de 2 a 3 (Cuadro 1). El promedio del ciclo larval fue de 16 días en P. mexicanus y 12 en P. hobbsi. Tanto P. mexicanus como 
Cuadro 1. Comparación del tiempo promedio (en días) del desarrollo larval y postlarval entre $P$. hobbsi y P. mexicanus, los valores entre paréntesis indican el intervalo en días

\begin{tabular}{llcccc}
\hline Especie & Zoea I & Zoea II & Zoea III & Postlarva I & Postlarva II \\
\hline P. hobbsi & $2(1-2)$ & $3(2-3)$ & $3(2-3)$ & $3(2-3)$ & 1 \\
P. mexicanus & $3(2-3)$ & $3(2-3)$ & $3(3-3.5)$ & $4(3-4)$ & $3(2-3)$ \\
\hline
\end{tabular}

P. hobbsi tienen un desarrollo larval breve, con 3 estadios de zoea y 2 estadios postlarvales.

\section{Palaemonetes mexicanus Strenth, 1976}

Zoea I

LT promedio. $4.71 \pm 0.10 \mathrm{~mm}$, intervalo $4.58-4.89 \mathrm{~mm}$ $(\mathrm{n}=6)$.

Caparazón (Fig. 1A). Sin espinas. Rostro ligeramente curvado hacia abajo, con un diente dorsal cerca de la base. Ojos sésiles. Abdomen (Fig. 1A) de 6 segmentos muy similares. Anténula (Fig. 1B). Pedúnculo con 3 artejos, primer artejo 2.6 veces más largo que el segundo; segundo artejo de igual longitud que el tercero; tercer artejo con 1 seta plumosa apical y 1 flagelo con 3 setas plumosas apicales. Antena (Fig. 1C). Birrámea. Protópodo sin artejos. Endópodo (flagelo) más pequeño que el exópodo (escafocerito). Endópodo no segmentado. Escafocerito con 11 setas plumosas, cubriendo la parte distal del margen interno y con 1 espina diminuta en el margen distal externo. Mandíbula (Fig. 1D) sin palpo; proceso incisivo con 4 dientes agudos; proceso molar no desarrollado. Maxílula (Fig. 1E). Endópodo con 1 seta simple. Endito superior más largo que el endito inferior; endito superior con 4 setas simples; endito inferior con 3 setas simples. Maxila (Fig. 1F) con 2 enditos. Endito superior con 3 setas simples y endito inferior con 2 setas simples. Endópodo sin segmentar con 3 setas simples apicales. Exópodo (escafognatito) con 6 setas plumosas, margen inferior con 1 seta plumosa robusta. Primer maxilípedo (Fig. 1G) birrámeo. Protópodo con 3 setas simples internas. Exópodo con 3 artejos, segundo artejo 6 veces más largo que el primero; primero y tercer artejos casi de igual longitud. Tercer artejo con 3 setas simples apicales. Endópodo no segmentado, con 3 setas apicales simples. Segundo maxilípedo (Fig. 1H) birrámeo. Exópodo con 4 artejos, primero y segundo artejos de igual longitud; tercer artejo más largo que el resto, con 2 setas plumosas distomarginales; cuarto artejo con 3 setas plumosas apicales. Endópodo con 3 artejos, segundo artejo 2 veces más largo que el primero y el tercero. Segundo artejo con 2 setas simples externas y tercer artejo con 2 setas simples apicales. Tercer maxilípedo (Fig. 1I) birrámeo. Exópodo con 2 artejos, primer artejo 4.7 veces más largo que el segundo. Primer artejo con 1 seta simple interna y 2 setas plumosas apicales; segundo artejo con 3 setas plumosas apicales. Endópodo con 3 artejos, primero y segundo similares en longitud y más largos que el tercero. Segundo artejo con 1 seta simple externa; tercer artejo con 3 setas simples apicales. Primero, segundo y tercer pereiópodos (Fig. 1J, 1-3) birrámeos, con exópodo no segmentado. Endópodos del primero y el segundo pereiópodos con quela no funcional. Cuarto y quinto pereiópodos (Fig. 1J, 4-5) sin exópodos. Pleópodos (Fig. 1K, 1-5) pequeños, unisegmentados. Telson (Fig. 1L) triangular, con 14 setas plumosas en el margen distal.

\section{Zoea II}

LT promedio. $5.30 \pm 0.06 \mathrm{~mm}$, intervalo 5.23-5.42 $\mathrm{mm}$ $(\mathrm{n}=6)$.

Caparazón (Fig. 2A). Similar al estadio anterior. Abdomen (Fig. 2A) sin cambios notables. Anténula (Fig. 2B). Pedúnculo sin modificaciones. Primer artejo con estilocerito y 3 veces más largo que el segundo y tercer artejo; ápice del tercer artejo sin cambios en el patrón de setas. Antena (Fig. 2C). Protópodo sin cambios. Endópodo (flagelo) con 5 artejos, quinto artejo más largo que el resto de los artejos. Exópodo (escafocerito) sin cambios en la ornamentación. Mandíbula (Fig. 2D) similar al estadio anterior, pero proceso molar con 5 dientes. Maxílula (Fig. 2E) similar al estadio anterior, endito superior con 5 setas simples. Maxila (Fig. 2F) con 3 enditos, endito superior con 3 setas simples; endito medio e inferior con 2 setas simples. Primer maxilípedo (Fig. 2G). Exópodo con 4 artejos, segundo y tercero más largos que primero y cuarto. Tercer artejo con 1 seta simple interna y cuarto artejo con 2 setas simples apicales. Endópodo con 3 artejos similares en longitud; tercer artejo con 2 setas simples apicales. Segundo maxilípedo (Fig.2H) similar al estadio anterior. Tercer maxilípedo (Fig. 2I). Exópodo con 3 artejos, segundo artejo 7 veces más largo que el primer artejo; tercer artejo 2 veces más largo que el primer artejo; segundo artejo con 2 setas simples apicales y tercer artejo con 3 setas plumosas largas apicales. Endópodo con 4 artejos, primer artejo 2.5 veces más largo que el resto de artejos. Primer artejo con 3 setas simples; segundo artejo con 1 seta simple; tercer artejo con 2 setas simples distomarginales y cuarto artejo con 3 setas plumosas apicales. Primero, segundo y tercer 
pereiópodos (Fig. 2J, 1-3). Endópodos del primero y segundo pereiópodos con quela no funcional. Exópodos con 4 setas plumosas apicales. Cuarto y quinto pereiópodos (Fig. 2J, 4-5). Endópodos con mayor numero de artejos. Pleópodos (Fig. 2K) bisegmentados. Telson (Fig. 2L) similar, pero aparecen los primordios de los urópodos.

\section{Zoea III}

LT promedio, $5.50 \pm 0.05 \mathrm{~mm}$, intervalo $5.42-5.55 \mathrm{~mm}$ $(\mathrm{n}=4)$.

Caparazón (Fig. 3A) sin espina. Rostro con 2 dientes dorsales cerca de la base y ojo pedunculado. Abdomen (Fig. 3A) sin cambios notables. Anténula (Fig. 3B). Pedúnculo con 3 artejos, primer artejo 2.5 veces más largo que el segundo artejo y 4 veces más largo que el tercer artejo. Primer artejo con 4 setas plumosas en cada margen; segundo artejo con 1 seta plumosa externa y 3 setas plumosas internas; tercer artejo sin cambios en ornamentación. Antena (Fig. 3C). Protópodo desnudo. Endópodo (flagelo) más largo que el escafocerito, con 7 artejos desnudos. Escafocerito con 12 setas plumosas cubriendo la parte distal y margen interno; y 1 espina en el margen distal externo. Mandíbula (Fig. 3D). Proceso incisivo y proceso molar con 6 dientes agudos. Maxílula (Fig. 3E). Endito superior e inferior cada uno con 5 setas simples de distinta talla. Maxila (Fig. 3F). Primer endito con 2 setas simples; segundo y tercer endito con 3 setas simples. Endópodo sin cambios. Exópodo (escafognatito) con 18 setas plumosas y 1 seta plumosa robusta en su margen inferior. Primer maxilípedo (Fig. 3G). Protópodo con 7 setas simples internas. Exópodo con 4 artejos, tercer artejo más largo que el resto de los artejos; cuarto artejo con 3 setas plumosas apicales. Endópodo con segundo artejo más largo que primero y tercer artejo; segundo artejo con 1 seta simple distomarginal y tercer artejo con 3 setas plumosas apicales. Segundo maxilípedo (Fig. $3 \mathrm{H}$ ). Protópodo con 3 setas simples internas. Exópodo con 4 artejos, tercer artejo más largo que el resto de artejos. Tercer artejo con 1 seta plumosa interna y cuarto artejo con 4 setas plumosas largas apicales. Endópodo con 5 artejos casi iguales en longitud; cuarto artejo con 1 seta simple distomarginal y quinto artejo con 3 setas plumosas apicales. Tercer maxilípedo (Fig. 3I). Protópodo con 3 setas simples externas. Exópodo con 3 artejos, segundo artejo 5 veces más largo que el primero y tercero. Segundo artejo con 1 seta plumosa externa y tercer artejo con 4 setas plumosas largas apicales. Endópodo con 5 artejos, segundo artejo más largo que el resto de artejos; tercero, cuarto y quinto artejos similares en longitud; primer artejo con 1 seta simple externa; segundo artejo con 3 setas simples externas y 1 seta simple interna; tercero y cuarto artejos con 2 setas simples distomarginales y quinto artejo con 4 setas plumosas apicales. Primero y segundo pereiópodos (Fig. 4 J, 1-2). Endópodos con 1 quela funcional. Exópodos más desarrollados. Tercero, cuarto y quinto pereiópodos (Fig. 3J, 3-5) sin cambios morfológicos. Pleópodos (Fig. 3K) bisegmentados y más desarrollados. Telson (Fig. 3L) con márgenes laterales expandidos. Urópodos (Fig. 3L). Exópodo con 8 setas plumosas en margen distal. Endópodo menor que exópodo y en desarrollo.

\section{Postlarva I}

LT promedio. $5.58 \pm 0.03 \mathrm{~mm}$, intervalo $5.55-5.61 \mathrm{~mm}$ $(\mathrm{n}=2)$.

Caparazón (Fig. 5A). Con 1 espina bien desarrollada en el margen anterior. Rostro con 2 dientes dorsales cerca de la base. Pedúnculo ocular visible. Abdomen (Fig. 5A). Sexto somita más desarrollado que el resto. Anténula (Fig. 5B). Pedúnculo con 4 artejos, primer artejo con estilocerito y 6 veces más largo que el resto de artejos; tercero y cuarto artejos 1.4 veces más largos que segundo artejo. Primer artejo con 4 setas plumosas en cada margen; segundo artejo con 2 setas plumosas distomarginales. Tercer artejo con 1 seta plumosa interna y cuarto artejo desnudo y con 2 flagelos del mismo tamaño. Flagelo interno con 4 artejos y 4 setas plumosas apicales; flagelo externo con 3 artejos y con 3 setas plumosas apicales. Antena (Fig. 5C). Endópodo (flagelo) más largo que el escafocerito, con 14 artejos desnudos. Exópodo (escafocerito) con15 setas plumosas cubriendo la parte distal y el margen interno y con 1espina en el margen distal externo. Mandíbula (Fig. 5D). Proceso incisivo con 5 dientes agudos. Proceso molar con 4 dientes agudos. Maxílula (Fig. 5E). Endito superior con 5 setas como espinas y endito inferior con 6 setas simples. Maxila (Fig. 5F). Ornamentación de los 3 enditos similar al estadio anterior. Endópodo simple con 2 setas simples apicales. Exópodo sin cambios en la ornamentación. Primer maxilípedo (Fig. 5G). Protópodo con 2 setas simples internas. Exópodo con 4 artejos, primero y segundo de igual longitud, ambos 3 veces más largos que el tercero y cuarto artejos, respectivamente. Segundo y tercer artejo con 2 setas plumosas distomarginales; cuarto artejo con 3 setas plumosas apicales. Endópodo con 4 artejos similares en longitud. Primer artejo con 1 seta simple externa; segundo y tercer artejo con 2 setas plumosas distomarginales y cuarto artejo con 3 setas plumosas apicales. Segundo maxilípedo (Fig. 5H). Protópodo con 2 setas simples internas. Exópodo con 5 artejos, segundo artejo mayor en longitud. Cuarto artejo con 1 seta simple interna y quinto artejo con 4 setas plumosas apicales. Endópodo con 5 artejos, segundo artejo más largo que el resto de los artejos. Primero y segundo artejos con 1 seta simple interna; cuarto artejo con 3 setas simples distomarginales; quinto artejo con 3 setas plumosas apicales. Tercer maxilípedo (Fig. 5I). Protópodo 


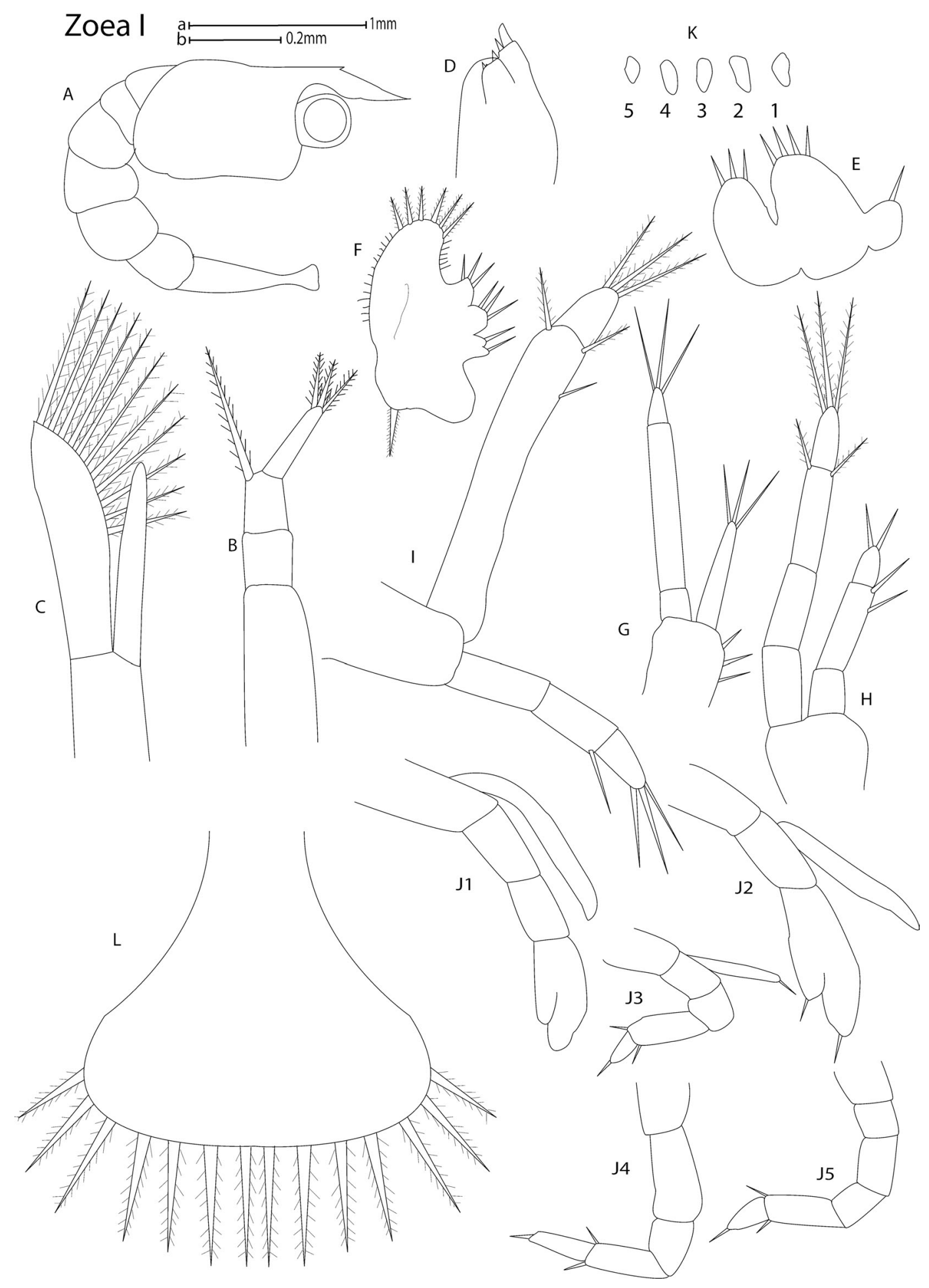

Figura 1. Palaemonetes mexicanus Strenth, 1976, zoea I: A, vista lateral; B, anténula; C, antena; D, mandíbula; E, maxílula; F, maxila; $\mathrm{G}$, primer maxilípedo; $\mathrm{H}$, segundo maxilípedo; I, tercer maxilípedo; J (1-5), primero al quinto pereiópodo; K (1-5), pleópodo; L, telson. Escala a: A; escala b: B, C, D, E, G, H, I, J, K, L. 


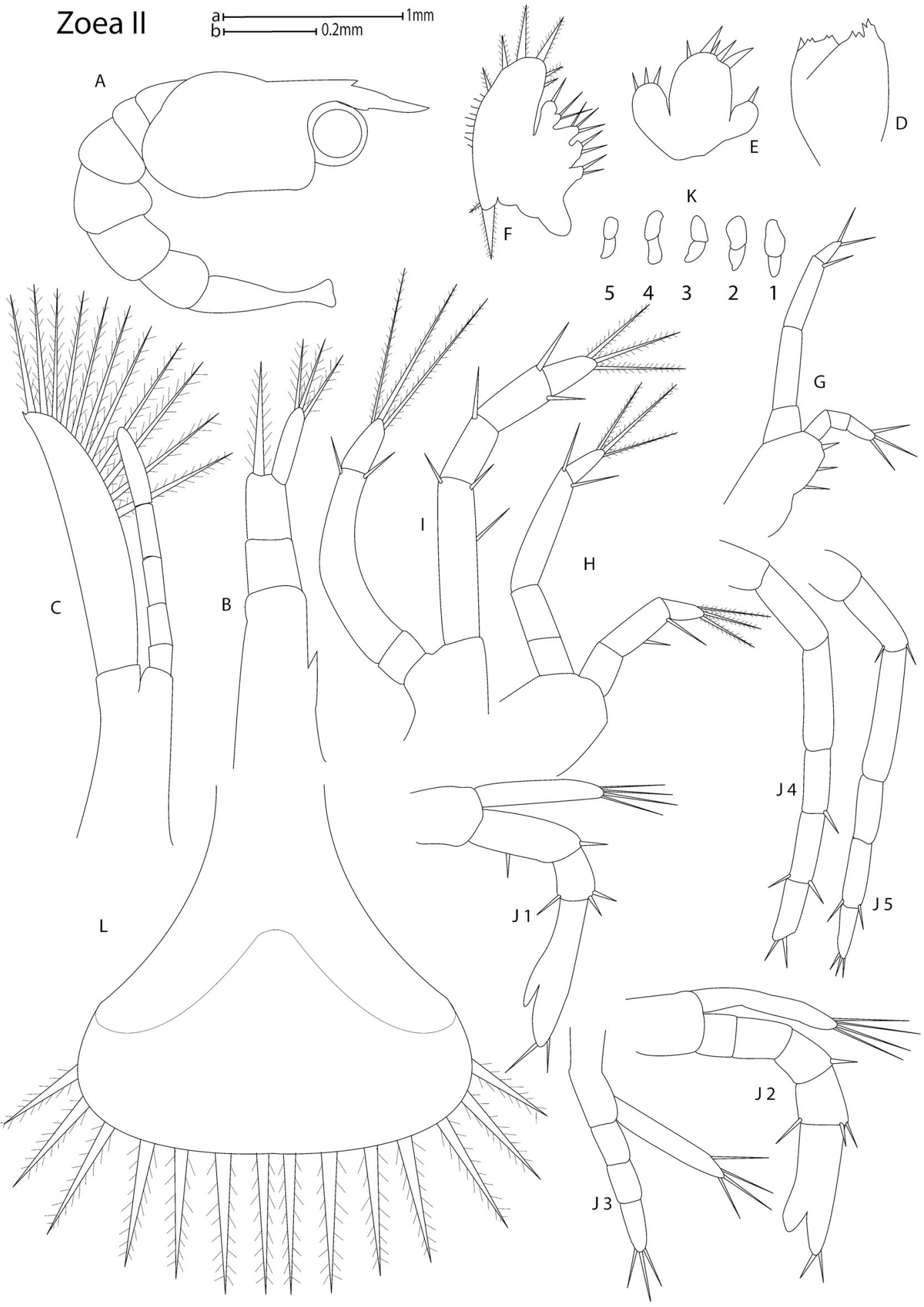

Figura 2. Palaemonetes mexicanus Strenth, 1976, zoea II: A, vista lateral; B, anténula; C, antena; D, mandíbula; E, maxílula; F, maxila; G, primer maxilípedo; H, segundo maxilípedo; I, tercer maxilípedo; J (1-5), primero al quinto pereiópodo; K (1-5), pleópodo; L, telson. Escala a: A; escala b: B, C, D, E, G, H, I, J, K, L. 




Figura 3. Palaemonetes mexicanus Strenth, 1976, zoea III: A, vista lateral; B, anténula; C, antena; D, mandíbula; E, maxílula; F, maxila; G, primer maxilípedo; H, segundo maxilípedo; I, tercer maxilípedo; K (1-5), pleópodo; L, telson y urópodos. Escala a: A; escala b: B, C, D, E, G, H, I, K, L. 


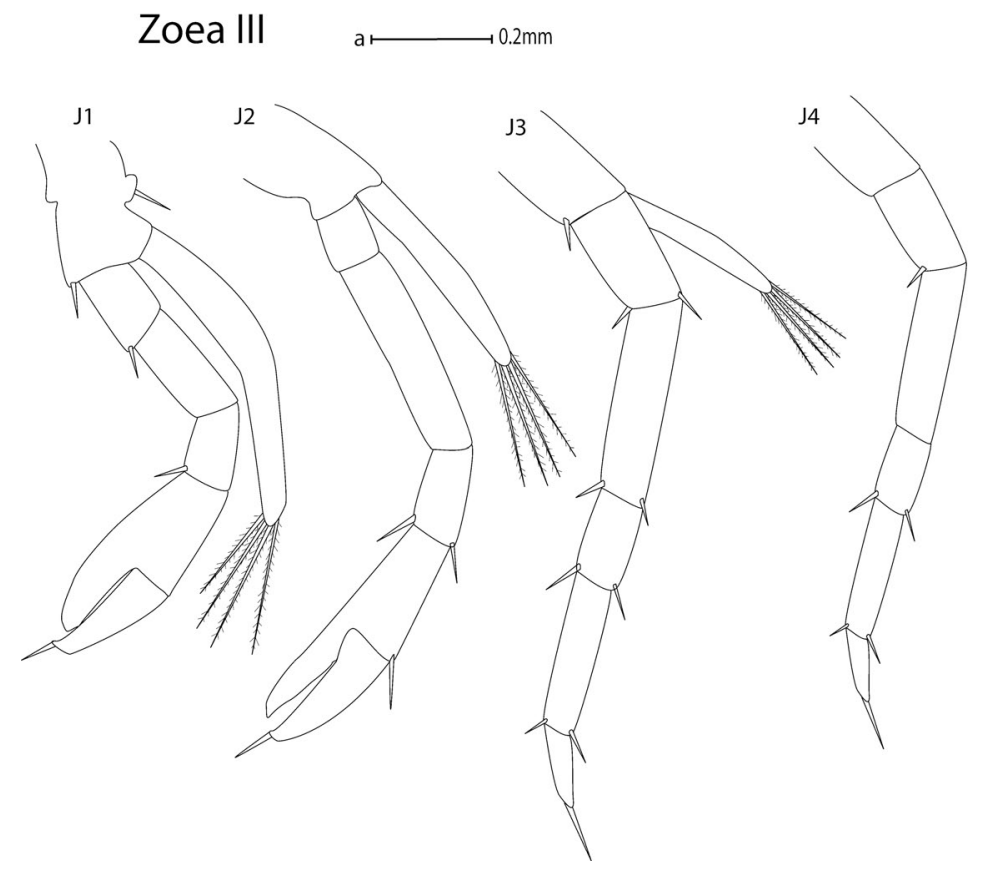

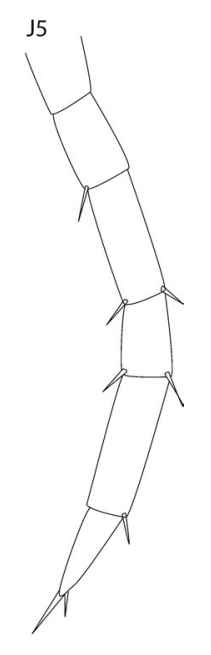

Figura 4. Palaemonetes mexicanus Strenth, 1976, zoea III; J (1-5), primero al quinto pereiópodo. Escala a: $\mathrm{J}$ sin cambios. Exópodo con 5 artejos, tercer artejo 1.6 veces más largo que el segundo artejo; primero y cuarto artejos similares en longitud; quinto artejo 2 veces más largo que el cuarto y el primer artejo. Tercero y cuarto artejos con 2 setas plumosas distomarginales y quinto artejo con 4 setas plumosas apicales. Endópodo similar en ornamentación al estadio larval anterior, solamente que el cuarto artejo en vez de 2 setas tiene 3 setas simples. Primero, segundo y tercer pereiópodos (Fig. 6J, 1-3). Endópodos del primero y segundo pereiópodos con quelas más desarrolladas. Exópodos del primero y segundo pereiópodos con 4 artejos; tercer artejo con 2 setas plumosas distomarginales; cuarto artejo con 4 setas plumosas apicales. Tercer pereiópodo con exópodo simple. Cuarto y quinto pereiópodos (Fig. 6J, 4-5) sin cambios morfológicos. Pleópodos (Fig. 5K) birrámeos, endópodos con 2 setas simples y exópodos con 3 setas simples. Telson (Fig. 5L) rectangular con el margen distal ligeramente bilobulado, con 12 setas plumosas en el margen distal y con 1espina en cada margen lateral. Urópodos (Fig. 5L) bien desarrollados. Exópodos con 7 setas plumosas en su margen distal y con 1espina distolateral. Endópodos con 4 setas plumosas distales.

\section{Postlarva II}

LT promedio, $5.98 \pm 0.07 \mathrm{~mm}$, intervalo $5.87-6.06 \mathrm{~mm}$ $(\mathrm{n}=6)$.

Caparazón (Fig.7A) similar a la postlarva I. Abdomen (Fig. 7A) sin cambios morfológicos. Anténula (Fig. 7B). Morfológicamente similar al estadio postlarval anterior. Estilocerito con 2 setas cortas plumosas. Tercer artejo del pedúnculo con 2 setas plumosas internas. Ambos flagelos similares en longitud y con 4 artejos. Antena (Fig. 7C). Protópodo sin cambios. Endópodo 1.5 veces más largo que el escafocerito, con 16 artejos; artejo distal con 3 setas cortas simples. Exópodo sin cambios morfológicos con respecto a la postlarva I. Mandíbula (Fig. 7D). Proceso incisivo con 3 dientes agudos. Proceso molar con 7 dientes. Maxílula (Fig. 7E). Endópodo bilobulado con 1 seta simple; endito superior con 5 setas simples distales, 5 setas diminutas submarginales y 2 simples setas laterales; endito inferior con 6 setas simples distales y 1 seta simple lateral. Maxila (Fig. 7F). Endito superior con 2 setas simples, endito medio con 4 setas simples; endito inferior separado de los anteriores y desnudo. Endópodo sin setas. Exópodo similar al estadio postlarval anterior. Primer maxilípedo (Fig. 7G) diferente en forma a los estadios larvales anteriores. Endito superior con 13 setas plumosas y el endito inferior con 2 setas simples. Epipodo con 5 setas plumosas. Endópodo desnudo y más corto que el exópodo. Exópodo con 4 artejos, cuarto artejo con 4 setas plumosas apicales. Segundo maxilípedo (Fig. 7H) diferente en forma a los estadios larvales anteriores. Coxa con 2 setas simples internas. Exópodo con 2 artejos casi iguales en longitud. Segundo artejo con 1 seta simple larga y robusta. Endópodo con 4 artejos, tercer artejo con 1 seta simple externa; cuarto artejo expandido y con 12 setas plumosas y 2 setas simples. Tercer maxilípedo (Fig. 7I). Protópodo con 2 setas simples externas. Endópodo con 6 artejos, tercer artejo más largo que el resto de los artejos. Primer artejo con 3 setas simples externas; segundo artejo 


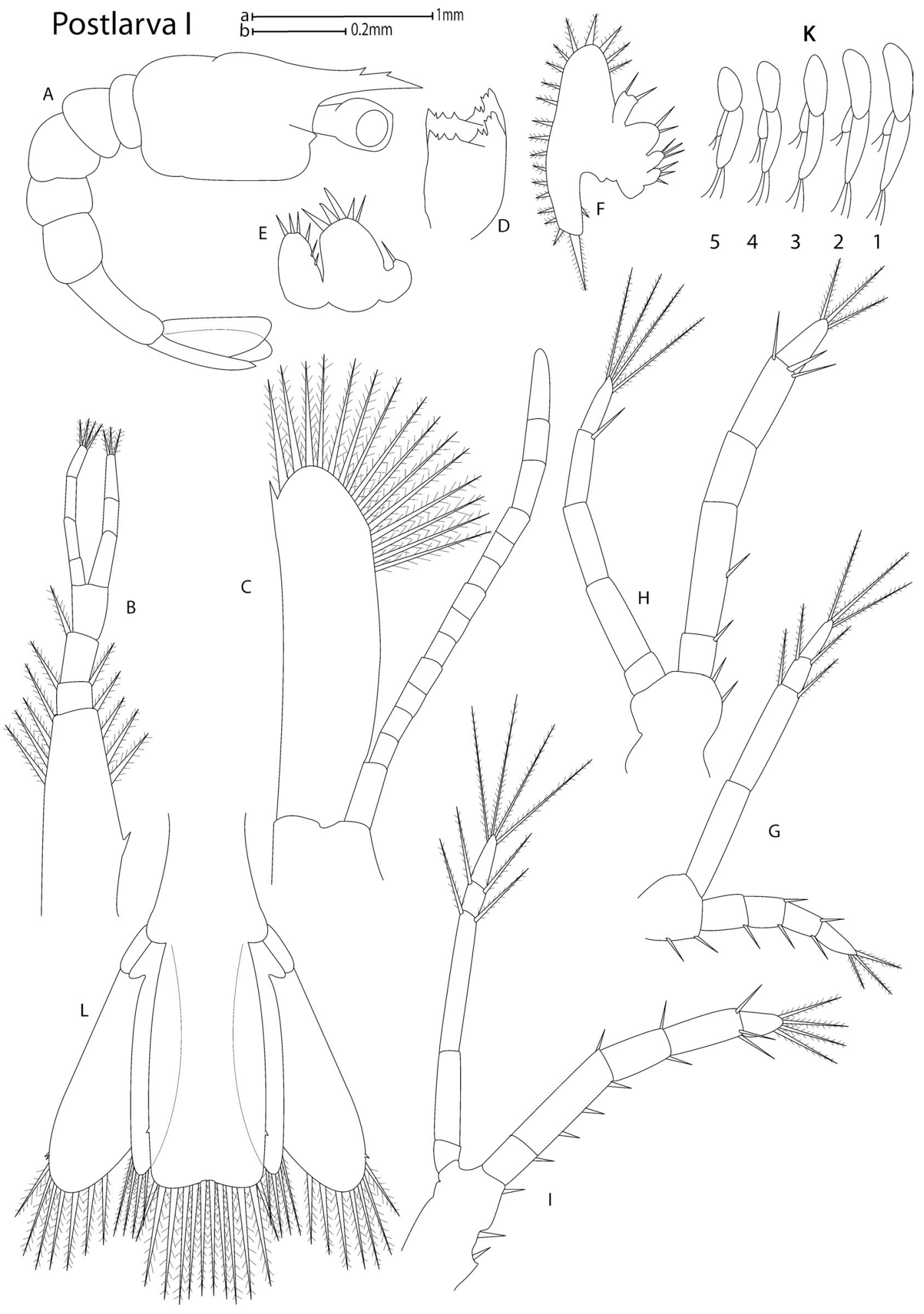

Figura 5. Palaemonetes mexicanus Strenth, 1976, postlarva I: A, vista lateral; B, anténula; C, antena; D, mandíbula; E, maxílula; F, maxila; G, primer maxilípedo; H, segundo maxilípedo; I, tercer maxilípedo; K (1-5), pleópodo; L, telson y urópodos. Escala a: A; escala b: B, C, D, E, G, H, I, K, L. 


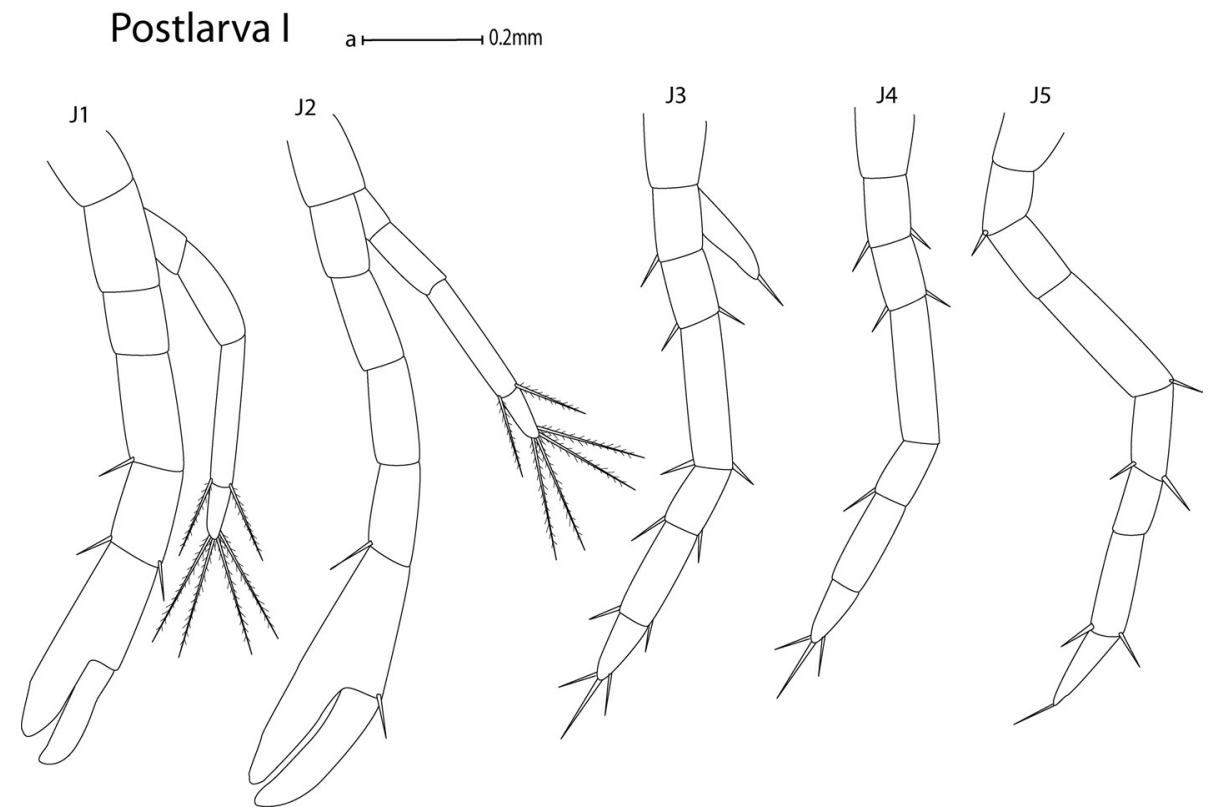

Figura 6. Palaemonetes mexicanus Strenth, 1976, postlarva I: J (1-5), primero al quinto pereiópodo. Escala a: J. con 1 seta simple distomarginal; tercer artejo con 2 setas simples distomarginales y 1seta simple externa; cuarto artejo con 2 setas simples distomarginales; quinto artejo con 2 setas plumosas en ambos márgenes; sexto artejo con 2 setas plumosas apicales. Exópodo con 3 artejos, tercer artejo con 3 setas plumosas apicales. Primero y segundo pereiópodos (Fig. 8J, 1-2). Endópodo del segundo pereiópodo más desarrollado que el primer endópodo y quela más desarrrollada. Exópodos reducidos. Tercero, cuarto y quinto pereiópodos (Fig. 8J, 3-5). Exópodos ausentes. Endópodos sin quelas. Pleópodos (Fig. 7K) birrámeos. Endópodos más desarrollados llevando 3 setas simples. Exópodos con 4 setas simples. Telson (Fig. 7L) rectangular, con 11 setas plumosas en el margen distal y con 1espina pequeña en cada margen lateral. Urópodos (Fig. 7L). Exópodos con 9 setas plumosas en el margen distal y con 1espina distolateral. Endópodos con 10 setas plumosas en el margen distal.

\section{Palaemonetes hobbsi Strenth, 1994}

\section{Zoea I}

LT promedio, $4.97 \pm 0.08 \mathrm{~mm}$, intervalo $4.84-5.11 \mathrm{~mm}$ $(n=10)$.

Caparazón (Fig. 9A). Sin espinas. Rostro ligeramente curveado hacia abajo, con 1 diente dorsal cerca de la base. Ojos sésiles. Abdomen (Fig. 9A) de 6 segmentos. Anténula (Fig. 9B). Pedúnculo con 3 artejos; primer artejo más largo que el segundo y tercer artejos; tercer artejo con 1 seta plumosa y 1 flagelo con 3 setas plumosas apicales. Antena (Fig. 9C). Birrámea. Protópodo sin artejos.
Exópodo (escafocerito) más largo que el endópodo, con 10 setas plumosas, cubriendo la parte distal del margen interno y con 1espina en el margen externo. Endópodo (flagelo) no segmentado y con 1 seta diminuta en el ápice. Mandíbula (Fig. 9D) sin palpo; proceso incisivo con 3 dientes agudos; proceso molar no desarrollado. Maxílula (Fig. 9E). Endópodo simple y desnudo. Endito superior más grande que el endito inferior, con 6 setas apicales; endito inferior con 1 seta simple. Maxila (Fig. 9F). Endito superior con 4 setas simples, endito medio con 3 setas simples y tercer endito con 2 setas simples. Endópodo sin segmentar, con 4 setas simples. Exópodo (escafognatito) con 5 setas plumosas apicales y en la parte inferior 1 seta plumosa robusta. Primer maxilípedo (Fig. 9G) birrámeo. Protópodo con 3 setas plumosas internas. Exópodo con 3 artejos, segundo artejo 4.5 veces y 2.5 veces más largo que el primero y el tercer artejos. Tercer artejo con 3 setas plumosas apicales y 1 seta plumosa interna. Endópodo con 3 artejos casi de igual longitud; primer artejo con 1 seta plumosa externa; segundo artejo con 1 seta plumosa interna y el tercero con 3 setas plumosas apicales. Segundo maxilípedo (Fig. 9H) birrámeo. Protópodo con 2 setas plumosas internas. Exópodo con 2 artejos, primer artejo 3 veces más largo que el segundo. Primer artejo con 1 seta plumosa distomarginal; segundo artejo con 4 setas plumosas apicales y 1 seta plumosa interna. Endópodo con 4 artejos, primer artejo más largo que el resto de los artejos. Tercer artejo con 2 setas plumosas distomarginales; cuarto artejo con 3 setas plumosas apicales. Tercer maxilípedo (Fig. 9I) birrámeo. Protópodo con 1 seta plumosa lateral 


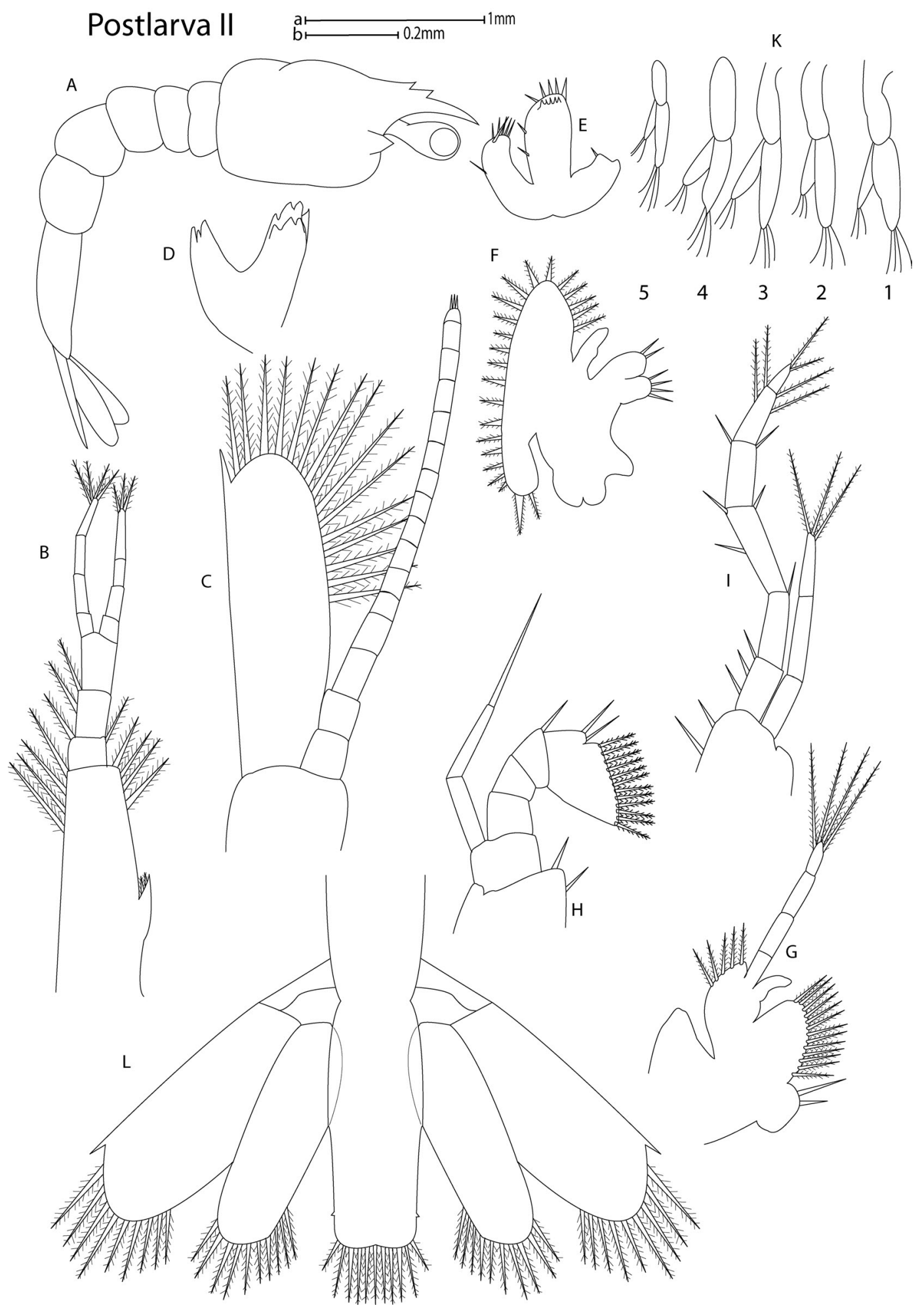

Figura 7. Palaemonetes mexicanus Strenth, 1976, postlarva II: A, vista lateral; B, anténula; C, antena; D, mandíbula; E, maxílula; F, maxila; G, primer maxilípedo; H, segundo maxilípedo; I, tercer maxilípedo; K (1-5), pleópodo; L, telson y urópodos. Escala a: A; escala b: B, C, D, E, G, H, I, K, L. 


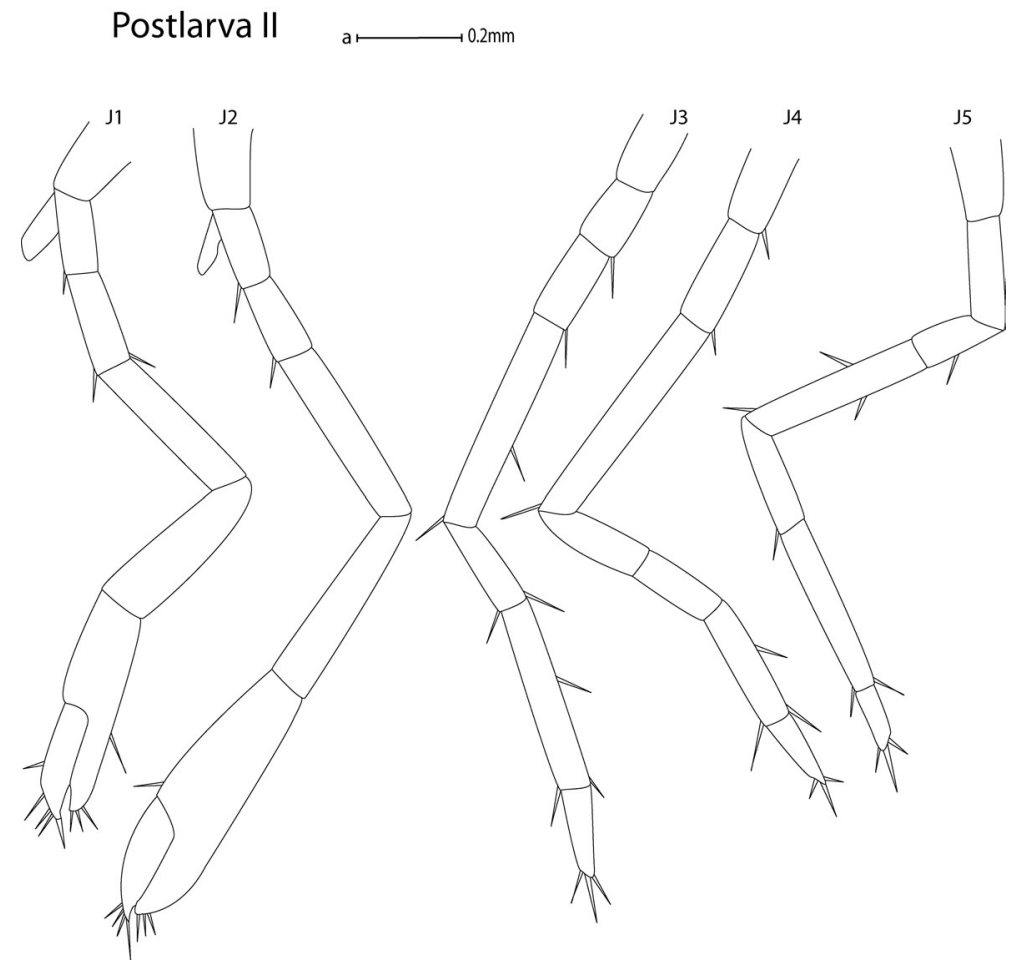

Figura 8. Palaemonetes mexicanus Strenth, 1976, postlarva II: J (1-5), primero al quinto pereiópodo. Escala a: J. interna. Exópodo no segmentado con 4 setas plumosas apicales y 3 setas plumosas en el margen interno. Endópodo con 5 artejos, primero y segundo artejo similares en longitud y más largo que el resto de los artejos. Primer artejo con 1seta plumosa interna; segundo artejo con 1 seta plumosa interna y 1 seta plumosa externa; tercer artejo con 1 seta plumosa externa; cuarto artejo con 2 setas plumosas internas y quinto artejo con 4 setas plumosas apicales. Primero, segundo y tercer pereiópodos (Fig. 9J 1-3) birrámeos. Exópodo no segmentado. Endópodo del primero y segundo pereiópodo con quela no funcional. Cuarto y quinto pereiópodos (Fig. 9J 4-5) sin exópodos. Pleópodos (Fig. 9K) pequeños, unisegmentados. Telson (Fig. 9L) triangular, con 13 setas plumosas en el margen distal.

\section{Zoea II}

LT promedio, $5.47 \pm 0.12 \mathrm{~mm}$, intervalo $5.35-5.74 \mathrm{~mm}$ $(n=6)$.

Caparazón (Fig. 10A). Rostro con 1 diente dorsal cerca de la base. Pedúnculo ocular visible. Abdomen (Fig. 10A) sin cambios notables. Anténula (Fig. 10B). Pedúnculo sin modificaciones en la longitud de los artejos. Primer artejo con 1 seta plumosa interna; segundo artejo con 3 setas plumosas internas; tercer artejo con 1 seta plumosa y 1 flagelo con 3 setas plumosas apicales. Antena (Fig. 10C). Protópodo sin cambios. Exópodo (escafocerito) de igual longitud que el endópodo, con 11 setas plumosas cubriendo la parte distal del margen interno y con 1 espina en el margen externo. Endópodo (flagelo) con 4 artejos y 2 setas simples apicales. Mandíbula (Fig. 10D). Proceso incisivo con 3 dientes agudos; proceso molar con 3 dientes pequeños y 1 diente agudo. Maxílula (Fig. $10 \mathrm{E})$. Endópodo sin cambios. Endito superior sin cambios; endito inferior con 4 setas simples y 1 distomarginal. Maxila (Fig. 10F). Endito superior e inferior con 2 setas simples y endito medio con 3 setas simples. Endópodo sin segmentar, con 1seta simple. Exópodo (escafognatito) con 21 setas plumosas distomarginales y en la parte inferior 1 seta plumosa robusta. Primer maxilípedo (Fig. 10G). Protópodo sin cambios. Exópodo con 3 artejos, segundo artejo más largo que otros artejos. Segundo artejo con 1 seta plumosa externa; tercer artejo con 3 setas plumosas apicales. Endópodo similar al anterior estadio, excepto que el segundo artejo con 2 setas plumosas en vez de 1 seta. Segundo maxilípedo (Fig. 10H) sin cambios notables, excepto en la relación de la longitud de los artejos del exópodo y endópodo. Tercer maxilípedo (Fig. 10I). Protópodo similar al estadio anterior. Exópodo con 3 artejos; tercer artejo más largo que el resto de los artejos. Tercer artejo con 4 setas plumosas apicales y 3 setas plumosas más distomarginales. Endópodo con 5 artejos; segundo y cuarto artejo más largos que los otros artejos. Primer artejo con 1 seta plumosa interna; segundo artejo con 1 seta 




Figura 9. Palaemonetes hobbsi Strenth, 1994, zoea I: A, vista lateral; B, anténula; C, antena; D, mandíbula; E, maxílula; F, maxila; G, primer maxilípedo; H, segundo maxilípedo; I, tercer maxilípedo; J (1-5), primero al quinto pereiópodo; K (1-5), pleópodo; L, telson. Escala a: A; escala b: B, C, D, E, G, H, I, J, K, L. 
plumosa interna y 1 seta plumosa externa; tercer artejo con 2 setas plumosas distomarginales; cuarto artejo con 2 setas plumosas internas y 1 seta plumosa externa; quinto artejo con 4 setas plumosas apicales. Primero, segundo y tercer pereiópodos (Fig. 10J, 1-3). Exópodos con 4 setas plumosas. Endópodo del primero y segundo pereiópodos con 1 quela no funcional. Cuarto y quinto pereiópodos (Fig. 10J, 4-5) sin exópodo. Endópodos con mayor número de artejos. Pleópodos (Fig. 10K) bisegmentados. Telson (Fig. 10L) similar al estadio larval anterior, apareciendo más desarrollados los urópodos.

\section{Zoea III}

LT promedio, $5.48 \pm 0.02 \mathrm{~mm}$, intervalo $5.45-5.51 \mathrm{~mm}$ $(n=2)$.

Caparazón (Fig. 11A) con espina en el margen anterior. Rostro con 2 dientes dorsales cerca de la base. Abdomen (Fig. 11A) sin cambios notables. Anténula (Fig. 11B). Primer artejo del pedúnculo con estilocerito y llevando 2 setas plumosas pequeñas; margen interno con 4 setas plumosas y margen externo con 2 setas plumosas. Segundo artejo con 3 setas plumosas internas; tercer artejo con 4 setas plumosas y 2 flagelos en el ápice. Flagelo interno con 2 artejos y 3 setas plumosas apicales; flagelo central unisegmentado y con 3 setas plumosas apicales. Antena (Fig. 11C). Exópodo con 13 setas plumosas apicales y con 1 espina en el margen externo. Endópodo notablemente más largo que el escafocerito, con 8 artejos y 3 setas simples apicales. Mandíbula (Fig. 11D). Proceso incisivo con 6 dientes agudos; proceso molar con 7 dientes pequeños. Maxílula (Fig. 11E). Endópodo con 1 seta simple. Endito superior con 6 setas apicales; endito inferior con 4 setas simples y 1 distomarginal. Maxila (Fig. 11F). Endito superior con 3 setas simples; endito medio e inferior con 2 setas simples. Endópodo sin artejos con 2 setas simples. Exópodo similar al estadio anterior, pero con 22 setas plumosas distomarginales. Primer maxilípedo (Fig. $11 \mathrm{G})$. Protópodo con 5 setas plumosas internas. Exópodo sin cambios. Segundo artejo con 1 seta plumosa interna; tercer artejo con 3 setas plumosas apicales y 1 subapical. Endópodo sin cambios con respecto al estadio anterior. Segundo maxilípedo (Fig. 11H). Sin cambios notables, excepto en la relación de la longitud de los artejos del exópodo y endópodo. Tercer maxilípedo (Fig. 11I). Sin cambios notables con respecto al estadio larval anterior. Primero y segundo pereiópodos (Fig. 11J, 1-2) birrámeos. Endópodos con 1 quela funcional. Exópodo del primer pereiópodo con 3 setas simples apicales y 2 setas simples cercanas al ápice. Exópodo del segundo pereiópodo con 4 setas simples apicales y 2 setas simples cercanas al ápice. Tercero, cuarto y quinto pereiópodos (Fig. 11J, 35) sin exópodo. Pleópodos (Fig. 11K) bisegmentados, más desarrollados. Telson (Fig. 11L) rectangular y cóncavo hacia el ápice, llevando 14 setas plumosas y 1 espina pequeña en cada margen. Urópodos (Fig. 11L). Exópodo con 16 setas plumosas; endópodo mas corto y sin setas.

\section{Postlarva I}

LT promedio, $5.84 \pm 0.03 \mathrm{~mm}$, intervalo $5.81-5.87 \mathrm{~mm}$ $(\mathrm{n}=2)$. Caparazón (Fig. 12A) similar a la zoea III. Abdomen (Fig. 12A) sin cambios. Anténula (Fig. 12B) sin cambios con respecto a la zoea III, excepto que ambos flagelos de igual tamaño y flagelo externo con 3 artejos. Antena (Fig. 12C). Exópodo con 18 setas plumosas, cubriendo la parte distal del margen interno y con 1 espina en el margen externo. Endópodo casi 2 veces de largo que el exópodo, con 10 artejos y con 3 setas simples apicales. Mandíbula (Fig. 12D). Proceso incisivo con 3 dientes agudos; proceso molar con 4 dientes pequeños. Maxílula (Fig. 12E). Endópodo sin cambios. Ambos enditos con 6 setas simples. Maxila (Fig. 12F) con 4 enditos. Primero y segundo enditos con 2 setas simples; tercero con 1 seta simple y el cuarto endito sin setas. Endópodo con 1 seta simple. Exópodo con 27 setas plumosas marginales y en la parte inferior con 1 seta plumosa robusta. Primer maxilípedo (Fig. $12 \mathrm{G}$ ) con cambios morfológicos notables. Enditos y coxa bien desarrollados. Endito superior con 8 setas simples y endito inferior con 7 setas simples. Epipodito desarrollado y con 3 setas simples. Exópodo con 2 artejos; primer artejo 3.3 veces más largo que el segundo artejo; segundo artejo con 2 setas simples apicales. Endópodo reducido y desnudo. Segundo maxilípedo (Fig. 12H) con cambios morfólogicos notables. Protópodo con 2 setas plumosas internas. Exópodo con 4 artejos y con 2 setas simples apicales. Endópodo con 3 artejos; segundo artejo con 1 seta simple externa y tercer artejo expandido en la parte apical y llevando 16 setas simples. Tercer maxilípedo (Fig. 12I). Protópodo con 3 setas simples internas. Exópodo reducido y con 2 segmentos, segundo artejo con 2 setas simples apicales. Endópodo con 5 artejos; segundo artejo más largo que el resto de los artejos. Primer artejo con 2 setas simples internas; segundo artejo con 5 setas simples internas y con 1 seta simple externa; tercer artejo con 2 setas simples internas y con 1 seta simple externa; cuarto artejo con 1 seta simple externa y 1 seta simple interna; quinto artejo con 2 setas simples apicales. Epipodito con 1 seta simple interna. Primero y segundo pereiópodos (Fig. 13J, 1-2) con exópodos reducidos. Endópodo con 1 quela funcional. Tercero, cuarto y quinto pereiópodos (Fig. 13J, 3-5) sin exópodo. Pleópodos (Fig. 12K) birrámeos. Telson (Fig. 12L). Rectangular, con 10 setas plumosas en el margen distal y 1 espina en ambos márgenes. Urópodos (Fig. 12L). Exópodos con 10 setas plumosas y 1 espina en ambos márgenes. Endópodo sin cambios. 


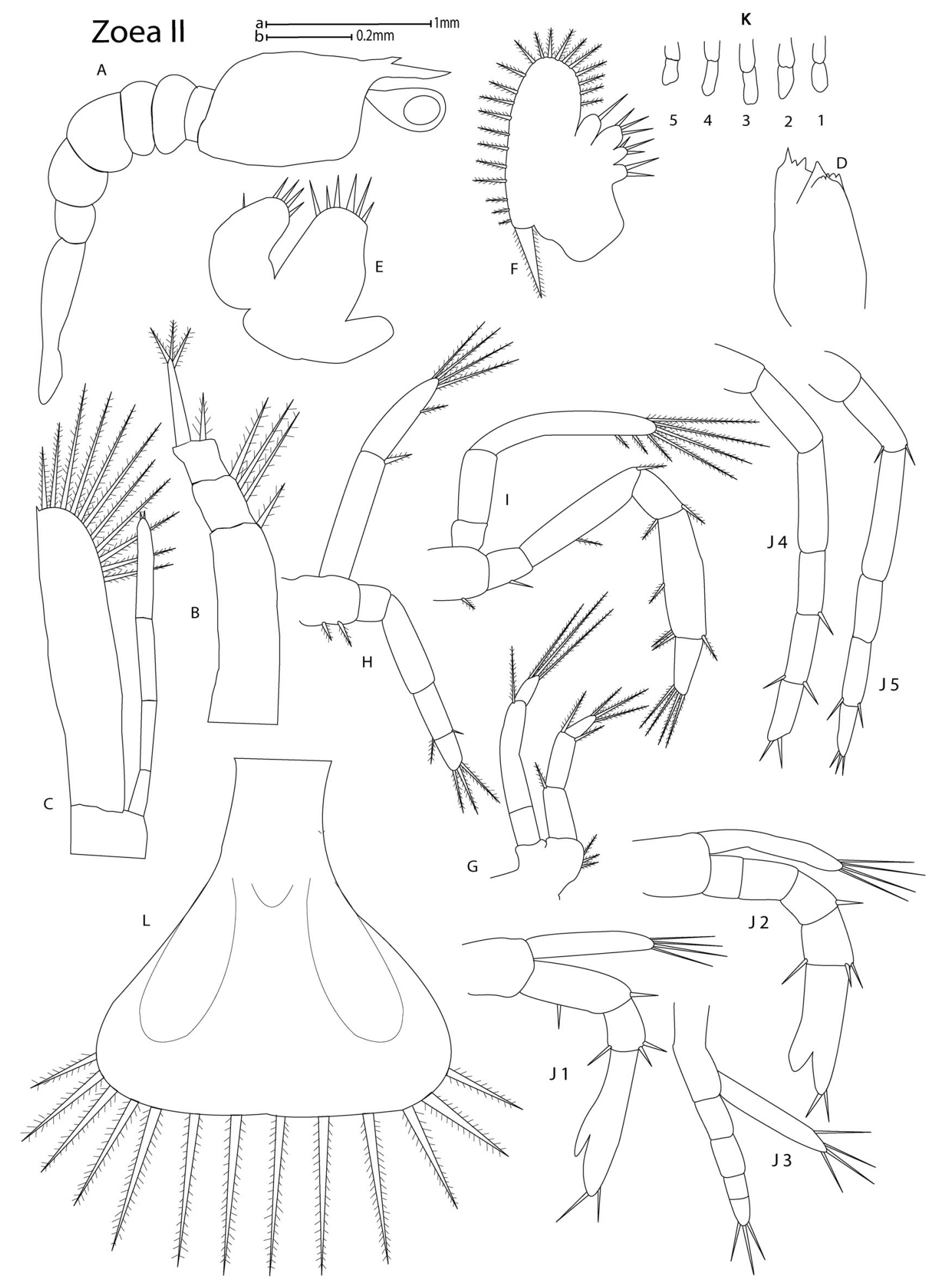

Figura 10. Palaemonetes hobbsi Strenth, 1994, zoea II: A, vista lateral; B, anténula; C, antena; D, mandíbula; E, maxílula; F, maxila; $\mathrm{G}$, primer maxilípedo; $\mathrm{H}$, segundo maxilípedo; I, tercer maxilípedo; J (1-5), primero al quinto pereiópodo; $\mathrm{K}$ (1-5), pleópodo; L, telson. Escala a: A; escala b: B, C, D, E, G, H, I, J, K, L. 


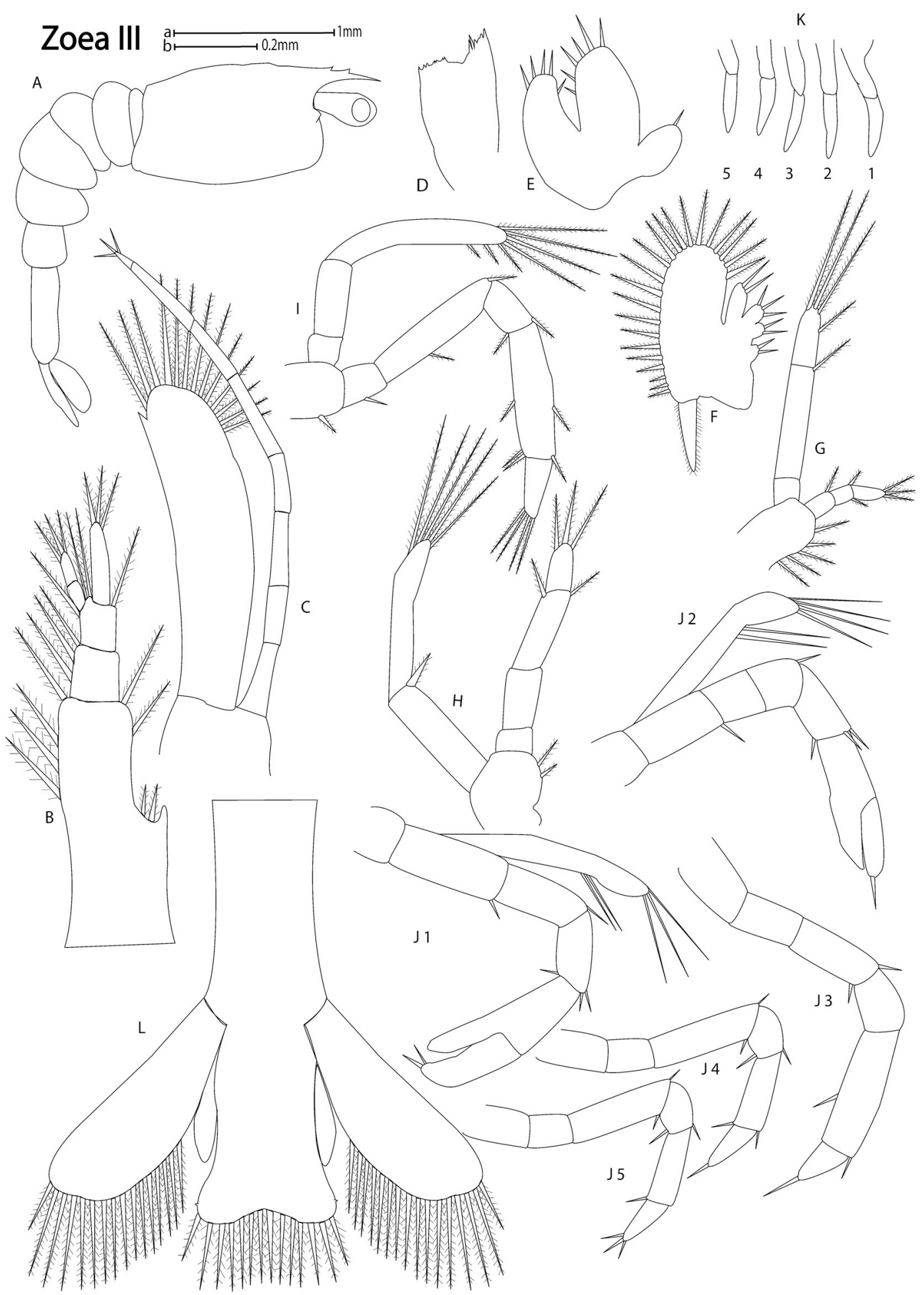

Figura 11. Palaemonetes hobbsi Strenth, 1994, zoea III: A, vista lateral; B, anténula; C, antena; D, mandíbula; E, maxílula; F, maxila; G, primer maxilípedo; H, segundo maxilípedo; I, tercer maxilípedo; J (1-5), primero al quinto pereiópodo; K (1-5), pleópodo; L, telson y urópodos. Escala a: A; escala b: B, C, D, E, G, H, I, J, K, L. 


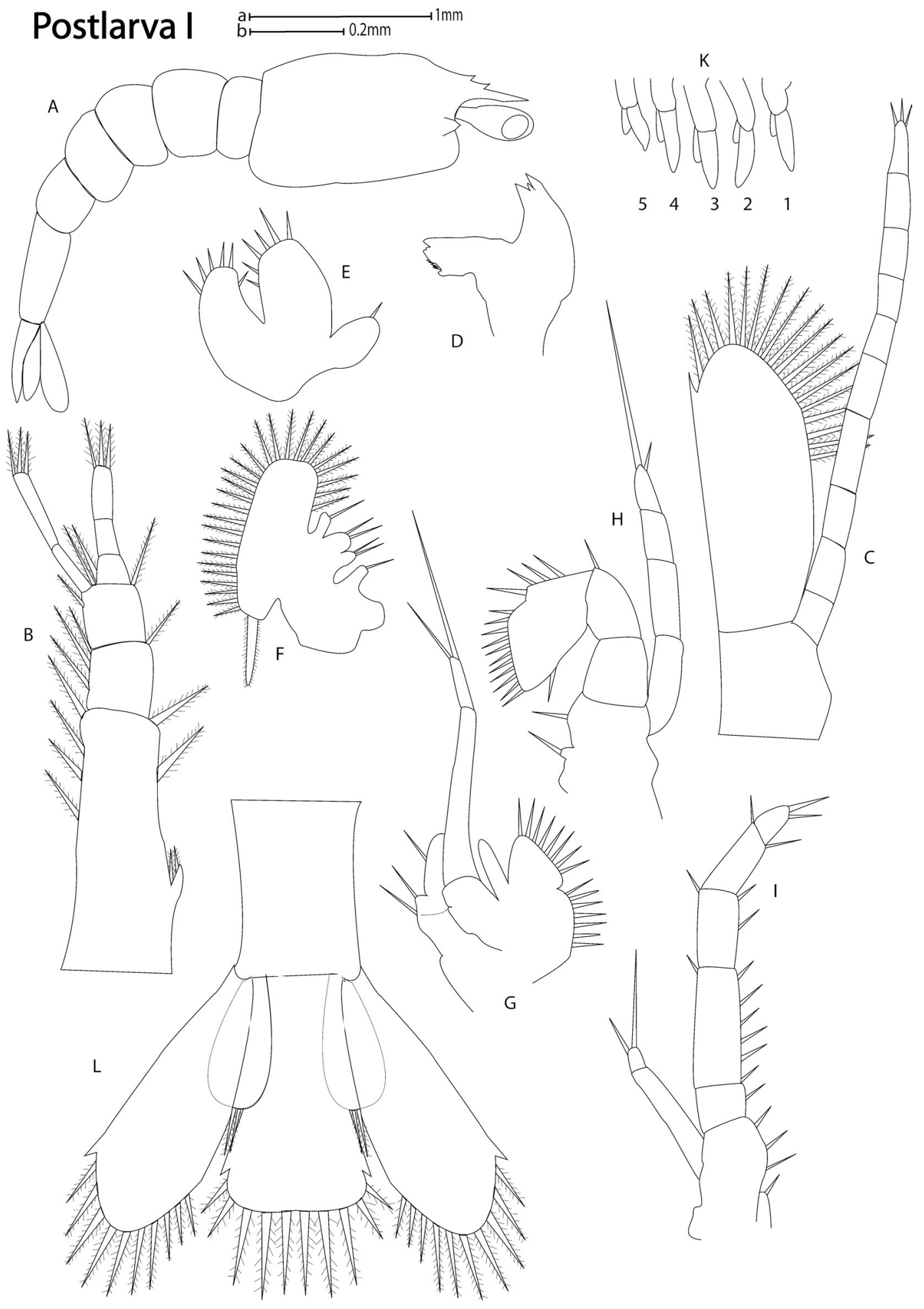

Figura 12. Palaemonetes hobbsi Strenth, 1994, postlarva I: A, vista lateral; B, anténula; C, antena; D, mandíbula; E, maxílula; F, maxila; G, primer maxilípedo; H, segundo maxilípedo; I, tercer maxilípedo; K (1-5), pleópodo; L, telson y urópodos. Escala a: A; escala b: B, C, D, E, G, H, I, K, L. 


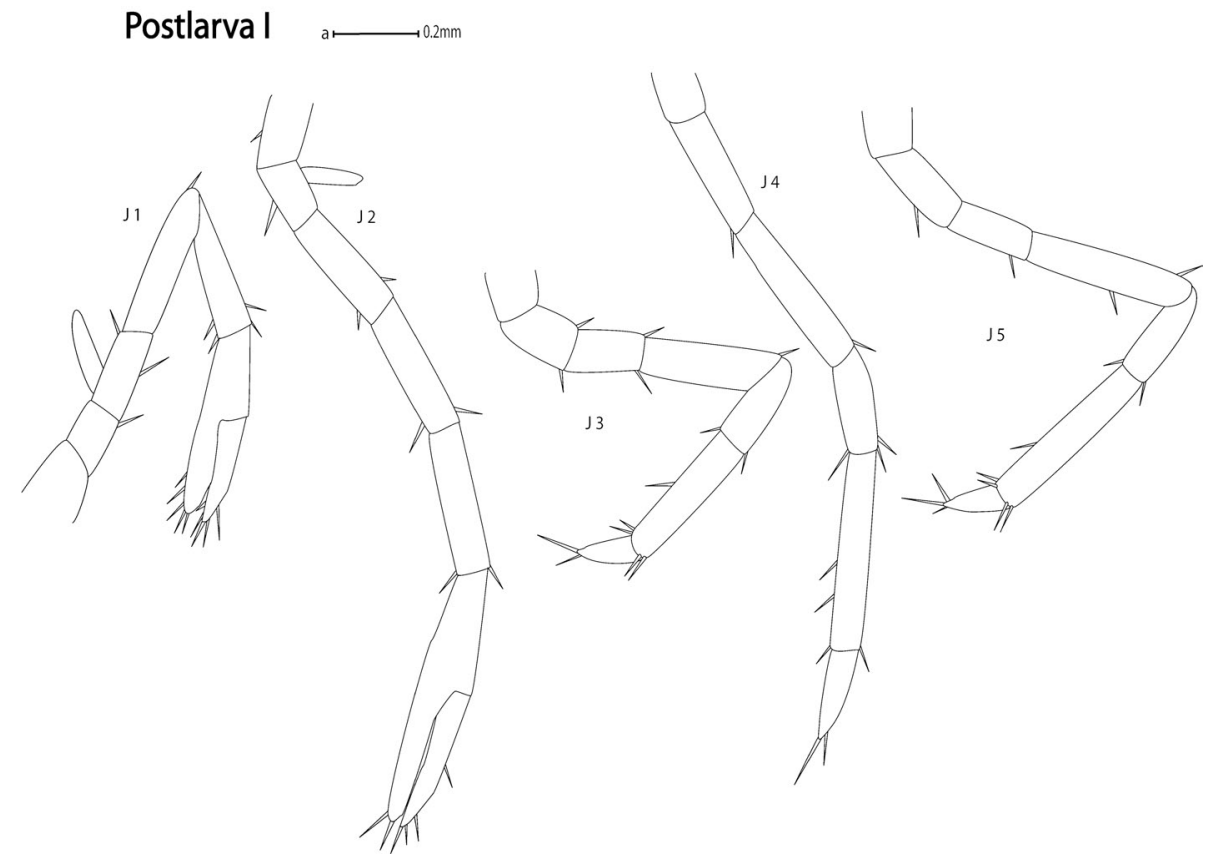

Figura 13. Palaemonetes hobbsi Strenth, 1994, postlarva I: J (1-5), primero al quinto pereiópodo. Escala a: J.

\section{Postlarva II}

LT promedio, $5.90 \pm 0.03 \mathrm{~mm}$, intervalo $5.87-5.94 \mathrm{~mm}$ $(\mathrm{n}=2)$.

Caparazón (Fig. 14A). Rostro con 3 dientes dorsales cerca de la base. Abdomen (Fig. 14A). Sexto somita más desarrollado. Anténula (Fig. 14B). Sin cambios con respecto a la postlarva I. Antena (Fig. 14C). Sin cambios con respecto a la postlarva I, excepto que el endópodo con 12 artejos y con 4 setas simples apicales. Mandíbula (Fig. 14D). Proceso incisivo con 4 dientes agudos; proceso molar con 6 dientes de distinto tamaño. Maxílula (Fig. 14E). Endópodo bilobulado y con 1 seta simple. Ambos enditos con 6 setas simples. Maxila (Fig. 14F) con 4 enditos. Primero y segundo enditos con 2 setas simples; tercero y cuarto enditos desnudos. Endópodo desnudo. Exópodo similar a la postlarva I, excepto que parte inferior con 2 setas plumosas. Primer maxilípedo (Fig. 14G). Enditos y coxa similares a la postlarva I. Endito superior con 12 setas simples y endito inferior con 4 setas simples. Exópodo con 2 artejos, ambos artejos desnudos. Endópodo notablemente reducido y desnudo. Segundo maxilípedo (Fig. 14H). Protópodo con 1seta simple externa. Exópodo no segmentado y con 2 setas simples apicales. Endópodo con 4 artejos; primer artejo con 1 seta simple externa; segundo y tercer artejo con 1 seta simple interna; cuarto artejo expandido en la parte apical y llevando 14 setas simples apicales. Tercer maxilípedo (Fig. 14I). Protópodo con 2 setas simples internas y 1 seta simple externa. Exópodo con 2 artejos; primer artejo 2 veces más largo que el segundo artejo. Primer artejo con 1 seta simple externa. Endópodo con 5 artejos; segundo artejo es más largo que el resto de los artejos; primer artejo con 1 seta simple interna; segundo artejo con 5 setas simples internas y 1 seta simple externa; tercer artejo con 3 setas simples internas y 1 seta simple externa; cuarto artejo con simple externa y 1 seta simple interna; quinto artejo con 2 setas simples apicales y 1 seta simple subapical interna. Primero y segundo pereiópodos (Fig. 15J, 1-2) similares a la postlarva I. Tercero, cuarto y quinto pereiópodos (Fig. 15J, 3-5) sin exópodo. Pleópodos (Fig. 14K) similares a la postlarva $\mathrm{I}$, pero con racimos de setas delgadas en ambas ramas. Telson (Fig. 14L). Similar a la postlarva I. Urópodos (Fig. 14L). Ambas ramas bien desarrolladas. Exópodo con 16 setas plumosas y 1 espina conspicua en su margen laterodistal; endópodo con 7 setas plumosas.

\section{Discusión}

Los miembros del género Palaemonetes son de talla pequeña a mediana (Jayachandran, 2001); alcanzan una longitud total de más de 35 mm (Hendrickx, 1995; Falciai y Palmerini, 2002). Sin embargo, Cheper (1992) menciona que las hembras grávidas de $P$. kadiakensis alcanzaron tallas de $46 \mathrm{~mm}$. Las hembras de este género son más grandes que los machos (Anderson, 1985). Las hembras grávidas de $P$. mexicanus y $P$. hobbsi presentaron tallas similares y no sobrepasaron los $13 \mathrm{~mm}$ de longitud del cefalotórax. 


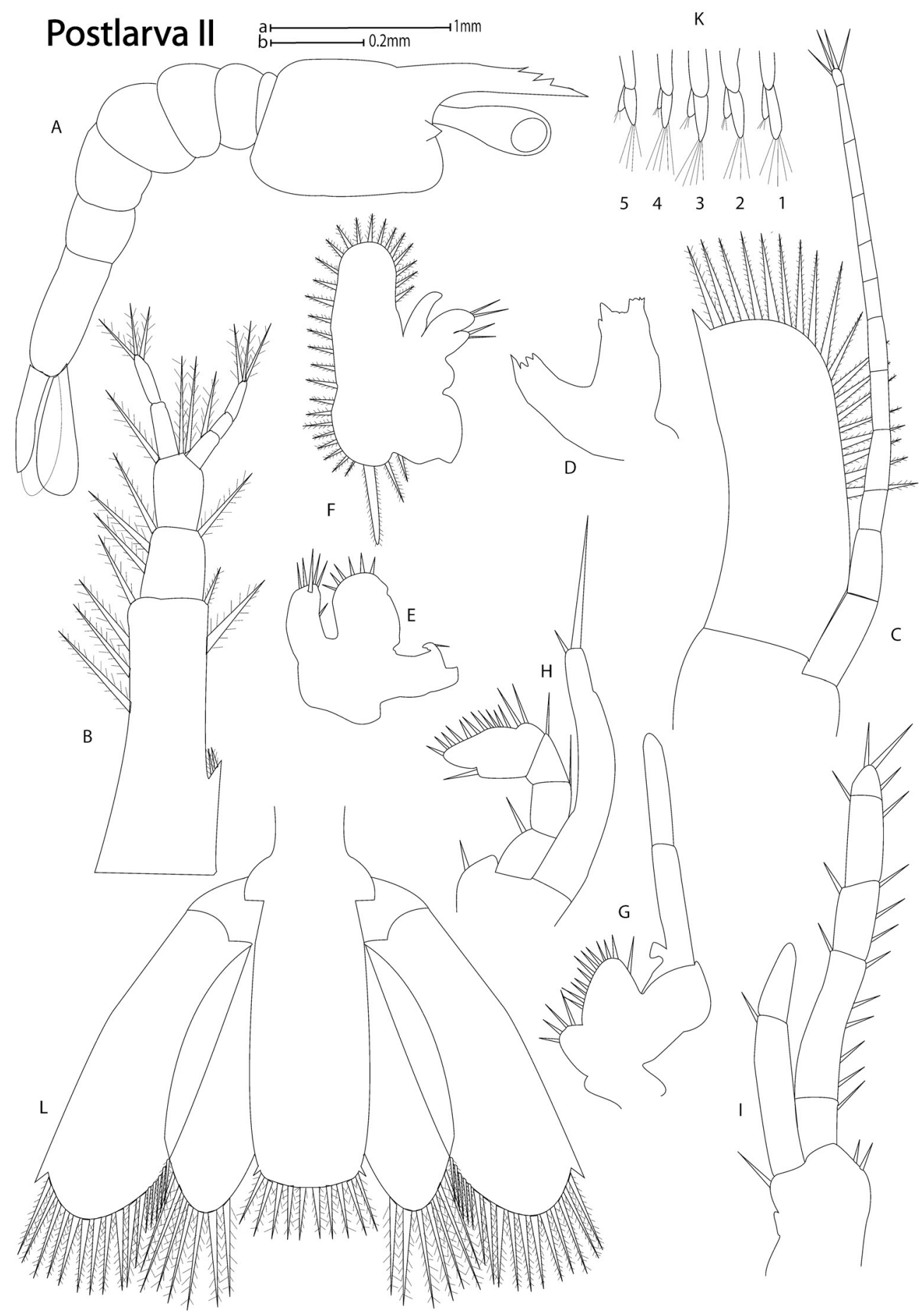

Figura 14. Palaemonetes hobbsi Strenth, 1994, postlarva II: A, vista lateral; B, anténula; C, antena; D, mandíbula; E, maxílula; F, maxila; G, primer maxilípedo; H, segundo maxilípedo; I, tercer maxilípedo; K (1-5), pleópodo; L, telson y urópodos. Escala a: A; escala b: B, C, D, E, G, H, I, K, L. 


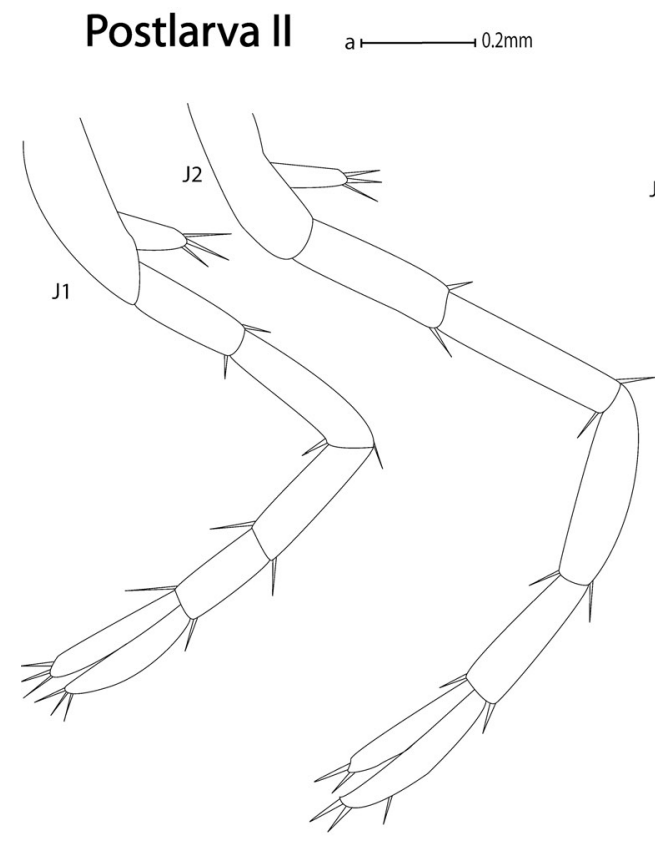

En otra especie mexicana, P. suttkusi, los machos y las hembras tienen una longitud promedio del cefalotórax de 6.77 y $7.23 \mathrm{~mm}$, respectivamente (Rodríguez-Almaraz et al., 1997). La tasa de crecimiento de Palaemonetes depende de la especie, sexo y hábitat (Anderson, 1985).

Se conoce el número de huevecillos que producen las hembras de varias especies de Palaemonetes de agua dulce y salobre; la producción de las especies de agua dulce de Norteamérica, incluyendo México, es la siguiente: $P$. cummingi entre 30 y 35 huevecillos (Dobkin, 1971), $P$. suttkussi de 11 a 18 huevecillos (Rodríguez-Almaraz et al., 1997), P. paludosus de 8 a 85 huevecillos (Beck y Cowell, 1976) y P. kadiakensis hasta 154 huevecillos (Meehan, 1936). Esta última también reside en ambientes salobres (Holthuis, 1952). Tanto P. hobbsi como P. mexicanus presentaron fecundidad baja, característica de las especies de agua dulce, con valores máximos de 31 y 17 huevecillos, respectivamente.

Sollaud (1923) y Strenth (1976) mencionan que las especies salobres de Palaemonetes producen mayor cantidad de huevecillos (hasta 486, como en P. pugio; Welsh, 1975), pero más pequeños que las especies de agua dulce. Esta reducción en talla de los huevecillos es consecuencia de la adaptación que sufren en ambientes con salinidad fluctuante, donde demandan mayor energía para la osmorregulación y para ello el vitelo cubre ese desgaste energético cuando se reproducen en bajas salinidades (Rodríguez et al., 1993).

El número de huevecillos se ha relacionado con la talla de las hembras de Palaemonetes (Sollaud, 1923; Corey y Reid, 1991; Falciai y Palmerini, 2002). En P. pugio se encontró una relación significativa entre ambos parámetros (Reinsel et al., 2001). En cambio en P. suttkusi, especie de agua dulce del norte de México, no se encontró una correlación significativa entre la talla y la fecundidad (Rodríguez-Almaraz et al., 1997). Sin embargo, para un análisis preciso de la producción de huevecillos en función de la talla de las hembras es necesario considerar las que porten huevecillos con un desarrollo embrionario temprano. Para la especie $P$. varians se definieron 5 estadíos de desarrollo embrionario (Rodríguez et al., 1993).

Por esta razón, en $P$. mexicanus y $P$. hobbsi no se analizó la relación talla hembras-huevecillos adheridos, debido a que las hembras grávidas recolectadas portaban huevecillos de diferente estadio embrionario, siguiendo el criterio de Rodríguez et al. (1993). El valor de la fecundidad no sólo depende del estadio de desarrollo embrionario de los huevecillos, también debe considerarse el éxito durante la oviposición e incubación, ya que hay pérdida de huevecillos en el proceso. Adicionalmente, deben contemplarse factores ambientales que afectan la producción de huevecillos, como temperatura, fotoperíodo, salinidad, alimento y calidad del agua (Lowe y Provenzano, 1990) o la limitación física del abdomen, puesto que solamente una porción de huevecillos son retenidos por los pleópodos (Reinsel et al., 2001).

Los huevecillos de P. mexicanus y de P. hobbsi tienen las características comúnes de los miembros de Palaemonetes; 
son granulosos y de color verde claro (Dobkin, 1971; Strenth, 1976) y forma ligeramente oval (Strenth, 1976; Corey y Reid, 1991). En P. varians la apariencia granulosa total o parcial del huevecillo corresponde a los estadios I al IV (Rodríguez et al., 1993).

La medida máxima de los huevecillos en su eje más largo fue mayor en los de $P$. mexicanus $(1.80 \mathrm{~mm})$ que en los de $P$. hobbsi $(1.60 \mathrm{~mm})$. Estas tallas están dentro del intervalo registrado $(1.4$ a $1.96 \mathrm{~mm}$, longitud máxima) para otras especies de Palaemonetes de agua dulce de Norteamérica y otras partes del mundo (Broad y Hubschman, 1963; Dobkin, 1963, 1971; Guerao, 1993; Rodríguez-Almaraz et al., 1997; Falciai y Palmerini, 2002) (Cuadro 2). Sin embargo, el tamaño de los huevecillos de Palaemonetes sufre cambios a medida que avanza el desarrollo embrionario (Dobkin, 1963; Guerao, 1993; Rodríguez et al., 1993). Estos cambios biométricos de los huevecillos reflejan los cambios morfogenéticos, como la elongación de la larva previa a la eclosión y la utilización del vitelo como fuente de energía (Rodríguez et al., 1993; Nazari et al., 2000).

El comportamiento de cuidado y protección de los huevecillos durante la incubación por parte de las hembras grávidas de $P$. mexicanus y $P$. hobbsi fue similar al comportamiento de $P$. antennarius que reside en agua dulce y salobre del Mediterráneo (Falciai y Palmerini, 2002). Las larvas recién eclosionadas de ambas especies tuvieron una natación lenta, pero la mayor parte del tiempo permanecieron inmóviles. La inmovilidad de las larvas zoea I de Palaemonetes se atribuye a que carecen de apéndices largos y la superficie dorsal está orientada hacia abajo, realizando movimientos horizontales (Anderson, 1985).

Las larvas y postlarvas de $P$. mexicanus y $P$. hobbsi en cultivo rechazaron como alimento larvas recién eclosionadas de Artemia, y sólo aceptaron partículas de hojuelas para peces, a partir de la zoea II. En otros estudios, larvas iniciales de P. paludosus, P. cummingi y
P. zariquieyi no fueron alimentadas, ya que subsisten del vitelo almacenado y hasta la fase larval tardía o postlarval comienzan a alimentarse (Dobkin, 1963, 1971; Guerao, 1993).

Las larvas zoea I de P. mexicanus y $P$. hobbsi fueron diferentes en su talla promedio, pero están dentro del intervalo de talla de las larvas de otras especies de Palaemonetes, incluyendo P. kadiakensis, P. paludosus, $P$. antennarius, $P$. cummingi, $P$. zariquieyi y $P$. antrorum (Broad y Hubschman, 1963; Dobkin, 1963, 1971; Strenth et al., 1988; Guerao, 1993; Falciai y Palmerini, 2002). Sin embargo, las larvas de $P$. hobbsi $(5.11 \mathrm{~mm})$ alcanzan las tallas más grandes, como las de $P$. antrorum $(5.20 \mathrm{~mm})$ (Strenth et al., 1988).

El tiempo de desarrollo larval y postlarval de $P$. mexicanus es similar al registrado para las larvas de $P$. antennarius (Falciai y Palmerini, 2002). En cambio, para $P$. hobbsi su ciclo larval de 12 días fue casi igual al de $P$. paludosus (Dobkin, 1963). Sin embargo, la duración del ciclo larval es difícil de comparar entre las especies debido a la influencia de las condiciones experimentales a las que fueron sometidas (Pereira y García, 1995; Álvarez et al., 2002).

El desarrollo larval de los langostinos palémonidos consta de 3 tipos de desarrollo (Sollaud, 1923; Jalihal et al., 1993), que se presentan de igual forma en las especies de Palaemonetes y Macrobrachium (Dobkin, 1963, 1971). El tipo II consiste en un desarrollo parcialmente abreviado, con 3 estadios larvales y con 1 (Dobkin, 1963, 1971; Guerao, 1993; Falciai y Palmerini, 2002) o 2 fases postlarvales (Strenth et al., 1988). Las especies que presentan este tipo de desarrollo son habitantes de agua dulce y producen pocos huevecillos, pero más grandes que los de las especies marinas o salobres (Tipo I) (Sollaud, 1923; Dobkin, 1963; Jalihal et al., 1993). La tendencia de abreviar las fases larvales, como en los miembros de Palaemonetes de agua dulce, está relacionada con la abundancia de vitelo en los huevecillos, que permite continuar el desarrollo dentro del

Cuadro 2. Comparación del eje mayor (largo) y eje menor (ancho) de los huevecillos de algunas especies de Palaemonetes de Norteamérica, incluyendo México

\begin{tabular}{lccc}
\hline Especie & Intervalo eje mayor $(\mathrm{mm})$ & Intervalo eje menor $(\mathrm{mm})$ & Referencia \\
\hline P. hobbsi & $0.90-1.60$ & $0.80-1.10$ & Este estudio \\
P. mexicanus & $1.10-1.80$ & $0.70-1.40$ & Este estudio \\
P. paludosus & $1.10-1.80$ & $0.80-1.00$ & Dobkin, 1963 \\
P. kadiakensis & 1.40 & 1.10 & Broad y Hubschman, 1963 \\
P. cummingi & 1.40 & ---- & Dobkin, 1971 \\
P. suttkusi & 1.50 & 1.10 & Rodríguez-Almaraz et al., 1997 \\
P. pugio* & $0.60-0.90$ & $0.50-0.60$ & Broad, 1957 \\
\hline
\end{tabular}

\footnotetext{
* Habitante de ambientes estuarinos.
} 
huevo por más tiempo (Falciai y Palmerini, 2002), con la adaptación a los ambientes de agua dulce (Sollaud, 1923; Magalhaes y Walker, 1988; Strenth, 1991), y reducir el tiempo de exposición de las larvas a las corrientes rápidas de ambientes lóticos.

Las especies de Norteamérica que hasta el momento tienen un desarrollo parcialmente abreviado son $P$. paludosus (Dobkin, 1963), P. cummingi (Dobkin, 1971) y $P$. antrorum (Strenth et al., 1988; Strenth, 1991). Este mismo patrón de desarrollo fue observado en $P$. mexicanus y $P$. hobbsi que tienen una relación más cercana con $P$. antrorum por presentar 2 estadios postlarvales como esta especie (Strenth et al., 1988). El tipo de desarrollo larval en las especies mexicanas contribuye a consolidar la hipótesis de una relación sistemática cercana entre todas las especies de Palaemonetes de agua dulce de Norteamérica, incluyendo México, propuesta por Strenth et al. (1988).
Palaemonetes kadiakensis es la excepción dentro de este grupo, ya que su desarrollo es más parecido a las especies marinas (Broad y Hubschman, 1963; Falciai y Palmerini, 2002).

La descripción ilustrada de cada fase larval y postlarval de $P$. mexicanus y $P$. hobbsi muestra que tuvieron un patrón de desarrollo similar, pero hay caracteres morfológicos que permiten establecer diferencias de un estadio larval a otro de la misma especie y entre ambas especies. Las principales diferencias morfológicas se encontraron en la antena, anténula, apéndices bucales y telson. Esta comparación se basó en la composición de los artejos y patrón de setas de estos apéndices (Cuadros 3-7). La información morfológica de los pereiópodos y pleópodos no fue suficiente para establecer diferencias entre ambas especies. Cabe destacar que las zoea I de P. mexicanus y $P$. hobbsi tienen el endópodo de la antena no segmentado,

Cuadro 3. Diferencias morfológicas de la zoea I entre P. mexicanus y P. hobbsi

\begin{tabular}{|c|c|c|}
\hline & P. mexicanus & P. hobbsi \\
\hline Antena & $\begin{array}{l}\text { Exópodo con } 11 \text { setas plumosas; endópodo } \\
\text { no segmentado, ultimo artejo sin setas }\end{array}$ & $\begin{array}{l}\text { Exópodo con } 10 \text { setas plumosas; endópodo no } \\
\text { segmentado, ultimo artejo con } 1 \text { seta diminuta }\end{array}$ \\
\hline Proceso incisivo de la mandíbula & 4 dientes agudos & 3 dientes agudos \\
\hline $\begin{array}{l}\text { Maxílula, patrón de setas de } \\
\text { endópodo, endito superior e inferior }\end{array}$ & $1-4-3$ & $0-6-1$ \\
\hline Maxila & $\begin{array}{l}\text { Endópodo con } 3 \text { setas simples; exópodo } \\
\text { con } 6 \text { setas plumosas; } 2 \text { enditos }\end{array}$ & $\begin{array}{l}\text { Endópodo con } 4 \text { setas simples; exópodo con } 5 \\
\text { setas plumosas; } 3 \text { enditos }\end{array}$ \\
\hline Primer maxilípedo & Endópodo no segmentado & Endópodo con 3 artejos \\
\hline Segundo maxilípedo & $\begin{array}{l}\text { Protopodo sin setas; exópodo con } 4 \text { artejos; } \\
\text { endópodo con } 3 \text { artejos }\end{array}$ & $\begin{array}{l}\text { Protopodo con } 2 \text { setas plumosas; exópodo con } \\
2 \text { artejos; endópodo con } 4 \text { artejos }\end{array}$ \\
\hline Tercer maxilípedo & $\begin{array}{l}\text { Protopodo sin setas, exópodo con } 2 \text { artejos; } \\
\text { endópodo con } 3 \text { artejos }\end{array}$ & $\begin{array}{l}\text { Protopodo con } 1 \text { seta plumosa; exópodo no } \\
\text { segmentado; endópodo con } 5 \text { artejos }\end{array}$ \\
\hline Telson & 14 setas plumosas & 13 setas plumosas \\
\hline
\end{tabular}

Cuadro 4. Diferencias morfológicas de la zoea II entre P. mexicanus y P. hobbsi

\begin{tabular}{|c|c|c|}
\hline & P. mexicanus & P. hobbsi \\
\hline Pedúnculo de la anténula & $\begin{array}{l}\text { Estilocerito presente; sin setas en los primeros } \\
2 \text { artejos }\end{array}$ & $\begin{array}{l}\text { Estilocerito ausente; con } 1 \text { y } 3 \text { setas plumosas } \\
\text { en los } 2 \text { primeros artejos }\end{array}$ \\
\hline Antena & Endópodo con 5 artejos, ultimo artejo sin setas & $\begin{array}{l}\text { Endópodo con } 4 \text { artejos, ultimo artejo con } 2 \\
\text { setas diminutas }\end{array}$ \\
\hline Proceso molar de la mandíbula & 5 dientes agudos & 4 dientes agudos \\
\hline $\begin{array}{l}\text { Maxílula, patrón de setas de } \\
\text { endópodo, endito superior e } \\
\text { inferior }\end{array}$ & $1-5-3$ & $0-6-5$ \\
\hline Maxila & $\begin{array}{l}\text { Endópodo con } 3 \text { setas simples; exópodo con } \\
6 \text { setas plumosas; patrón de setas en enditos, } \\
3-2-2\end{array}$ & $\begin{array}{l}\text { Endópodo con } 1 \text { seta simple; exópodo con } 21 \\
\text { setas plumosas; patrón de setas en enditos, } \\
2-3-2\end{array}$ \\
\hline Primer maxilípedo & Exópodo con 4 artejos; endópodo con 3 artejos & Exópodo con 3 artejos; endópodo con 3 artejos \\
\hline Segundo maxilípedo & $\begin{array}{l}\text { Protopodo sin setas; exópodo con } 4 \text { artejos } \\
\text { endópodo con } 3 \text { artejos }\end{array}$ & $\begin{array}{l}\text { Protopodo con } 2 \text { setas plumosas; exópodo con } \\
2 \text { artejos; endópodo con } 4 \text { artejos }\end{array}$ \\
\hline Tercer maxilípedo & $\begin{array}{l}\text { Protopodo sin setas, exópodo con } 3 \text { artejos; } \\
\text { endópodo con } 4 \text { artejos }\end{array}$ & $\begin{array}{l}\text { Protopodo con } 1 \text { seta plumosa; exópodo con } 3 \\
\text { artejos; endópodo con } 5 \text { artejos }\end{array}$ \\
\hline Telson & 14 setas plumosas & 13 setas plumosas \\
\hline
\end{tabular}


Cuadro 5. Diferencias morfológicas de la zoea III entre P. mexicanus y $P$. hobbsi

\begin{tabular}{|c|c|c|}
\hline & P. mexicanus & P. hobbsi \\
\hline Caparazón & $\begin{array}{l}\text { Sin espina en el margen anterior; rostro } \\
\text { con } 2 \text { dientes dorsales }\end{array}$ & $\begin{array}{l}\text { Con espina en el margen anterior; rostro con } \\
2 \text { dientes dorsales }\end{array}$ \\
\hline Pedúnculo de la anténula & Estilocerito sin setas; patrón de setas 8-4-0 & Estilocerito con 2 setas; patrón de setas 6-3-4 \\
\hline Antena & $\begin{array}{l}\text { Endópodo con } 7 \text { artejos, ultimo artejo sin } \\
\text { setas }\end{array}$ & $\begin{array}{l}\text { Endópodo con } 8 \text { artejos, ultimo artejo con } 3 \\
\text { setas diminutas }\end{array}$ \\
\hline Proceso molar de la mandíbula & 6 dientes agudos & 7 dientes agudos \\
\hline $\begin{array}{l}\text { Maxílula, patrón de setas de } \\
\text { endópodo, endito superior e inferior }\end{array}$ & $1-5-5$ & $1-6-5$ \\
\hline Maxila & $\begin{array}{l}\text { Endópodo con } 3 \text { setas simples; exópodo } \\
\text { con } 18 \text { setas plumosas; patrón de setas en } \\
\text { enditos, } 2-3-3\end{array}$ & $\begin{array}{l}\text { Endópodo con } 3 \text { setas simples; exópodo con } \\
22 \text { setas plumosas; patrón de setas en enditos, } \\
3-2-2\end{array}$ \\
\hline Primer maxilípedo & $\begin{array}{l}\text { Pedúnculo con } 7 \text { setas simples; exópodo } \\
\text { con } 4 \text { artejos; endópodo con } 3 \text { artejos }\end{array}$ & $\begin{array}{l}\text { Pedúnculo con } 5 \text { setas simples; exópodo con } \\
3 \text { artejos; endópodo con } 3 \text { artejos }\end{array}$ \\
\hline Segundo maxilípedo & $\begin{array}{l}\text { Protopodo con } 3 \text { setas simples; exópodo } \\
\text { con } 4 \text { artejos, endópodo con } 5 \text { artejos }\end{array}$ & $\begin{array}{l}\text { Protopodo con } 2 \text { setas plumosas; exópodo con } \\
2 \text { artejos; endópodo con } 4 \text { artejos }\end{array}$ \\
\hline Tercer maxilípedo & $\begin{array}{l}\text { Protopodo con } 3 \text { setas simples, exópodo } \\
\text { con } 3 \text { artejos; endópodo con } 5 \text { artejos }\end{array}$ & $\begin{array}{l}\text { Protopodo con } 1 \text { seta plumosa; exópodo con } 3 \\
\text { artejos; endópodo con } 5 \text { artejos }\end{array}$ \\
\hline Telson & Triangular & Rectangular \\
\hline Urópodos & Exópodo con 8 setas plumosas & Exópodo con 16 setas plumosas \\
\hline
\end{tabular}

Cuadro 6. Diferencias morfológicas de la postlarva I entre $P$. mexicanus y $P$. hobbsi

\begin{tabular}{|c|c|c|}
\hline & P. mexicanus & P. hobbsi \\
\hline Pedúnculo de la anténula & $\begin{array}{l}\text { Pedúnculo con } 4 \text { artejos; estilocerito sin setas; } \\
\text { patrón de setas } 8-2-1-0 \text {; flagelo interno con } 4 \\
\text { artejos y flagelo externo con } 3 \text { artejos }\end{array}$ & $\begin{array}{l}\text { Pedúnculo con } 3 \text { artejos; estilocerito con } 2 \\
\text { setas; patrón de setas 6-4-4; Flagelo interno } \\
\text { con } 2 \text { artejos y flagelo externo con } 3 \text { artejos }\end{array}$ \\
\hline Antena & $\begin{array}{l}\text { Endópodo con } 14 \text { artejos, ultimo artejo sin } \\
\text { setas; exópodo con } 15 \text { setas plumosas }\end{array}$ & $\begin{array}{l}\text { Endópodo con } 10 \text { artejos, ultimo artejo con } \\
3 \text { setas diminutas; exópodo con } 18 \text { setas } \\
\text { plumosas }\end{array}$ \\
\hline Proceso incisivo de la mandíbula & 5 dientes agudos & 3 dientes agudos \\
\hline $\begin{array}{l}\text { Maxílula, patrón de setas de } \\
\text { endópodo, endito superior e inferior }\end{array}$ & $1-5-6$ & $1-6-6$ \\
\hline Maxila & $\begin{array}{l}\text { Endópodo con } 2 \text { setas simples; exópodo con } \\
18 \text { setas plumosas; patrón de setas en enditos, } \\
2-3-3\end{array}$ & $\begin{array}{l}\text { Endópodo con } 1 \text { seta simple; exópodo } \\
\text { con } 27 \text { setas plumosas; patrón de setas en } \\
\text { enditos, } 2-2-1-0\end{array}$ \\
\hline Primer maxilípedo & $\begin{array}{l}\text { Exópodo con } 4 \text { artejos; endópodo con } 4 \\
\text { artejos }\end{array}$ & $\begin{array}{l}\text { Exópodo con } 2 \text { artejos; endópodo reducido } \\
\text { y desnudo }\end{array}$ \\
\hline Segundo maxilípedo & $\begin{array}{l}\text { Exópodo con } 5 \text { artejos; endópodo con } 5 \\
\text { artejos }\end{array}$ & $\begin{array}{l}\text { Exópodo con } 4 \text { artejos; endópodo con } 3 \\
\text { artejos, tercer artejo expandido distalmente }\end{array}$ \\
\hline Tercer maxilípedo & Exópodo y endópodo con 5 artejos & $\begin{array}{l}\text { Exópodo con } 2 \text { artejos reducidos; endópodo } \\
\text { con } 5 \text { artejos }\end{array}$ \\
\hline Primero y segundo pereiópodos & Exópodos segmentados y con setas plumosas & Exópodos reducidos \\
\hline Telson & $\begin{array}{l}\text { Margen distal ligeramente bilobulado con } 12 \\
\text { setas plumosas }\end{array}$ & $\begin{array}{l}\text { Margen distal continuo con } 10 \text { setas } \\
\text { plumosas }\end{array}$ \\
\hline Urópodos & Exópodo y endópodo bien desarrollados & Endópodo reducido \\
\hline
\end{tabular}

como lo ilustra Strenth (1976).

Dobkin(1971) considera que debidoal desconocimiento de la variación normal entre los individuos de la misma especie, en la diferenciación de especies de Palaemonetes la utilización del patrón de setas de los apéndices de cada estadio larval debe tomarse con cautela, En otras especies de Palaemonetes, como P. pugio y P. vulgaris, las diferencias morfológicas de sus larvas son muy leves; sin embargo, la distribución de los cromatóforos en la superficie ventral del abdomen puede servir para identificarlas (Broad, 1957). Aunque en este estudio no se consideró el patrón de distribución de cromatóforos de P. mexicanus y P. hobbsi, podría ser interesante examinar este carácter, pero implica observar organismos vivos o recién muertos. En el caso de 
Cuadro 7. Diferencias morfológicas de la postlarva II entre P. mexicanus y P. hobbsi.

\begin{tabular}{|c|c|c|}
\hline & P. mexicanus & P. hobbsi \\
\hline Rostro & 2 dientes dorsales & 3 dientes dorsales \\
\hline Pedúnculo de la anténula & $\begin{array}{l}\text { Pedúnculo con } 4 \text { artejos; patrón de setas 8-2-2- } \\
0 \text {; flagelo interno y externo con } 4 \text { artejos }\end{array}$ & $\begin{array}{l}\text { Pedúnculo con } 3 \text { artejos; patrón de setas 6- } \\
\text { 4-4; Flagelo interno con } 2 \text { artejos y flagelo } \\
\text { externo con } 3 \text { artejos }\end{array}$ \\
\hline Antena & $\begin{array}{l}\text { Endópodo con } 16 \text { artejos, ultimo artejo con } 3 \\
\text { setas diminutas }\end{array}$ & $\begin{array}{l}\text { Endópodo con } 12 \text { artejos, ultimo artejo con } \\
4 \text { setas simples }\end{array}$ \\
\hline Proceso incisivo de la mandíbula & 3 dientes agudos & 4 dientes agudos \\
\hline $\begin{array}{l}\text { Maxílula, patrón de setas de } \\
\text { endópodo, endito superior e inferior }\end{array}$ & $1-12-6$ & $1-6-6$ \\
\hline Maxila & $\begin{array}{l}\text { Endópodo desnudo; exópodo con } 21 \text { setas } \\
\text { plumosas; patrón de setas en enditos, 2-4-0 }\end{array}$ & $\begin{array}{l}\text { Endópodo desnudo; exópodo con } 27 \text { setas } \\
\text { plumosas; patrón de setas en enditos, } 2-2- \\
0-0\end{array}$ \\
\hline Primer maxilípedo & Exópodo con 4 artejos; endópodo reducido & $\begin{array}{l}\text { Exópodo con } 2 \text { artejos; endópodo } \\
\text { notablemente reducido y desnudo }\end{array}$ \\
\hline Segundo maxilípedo & Exópodo con 2 artejos; endópodo con 4 artejos & $\begin{array}{l}\text { Exópodo no segmentado; endópodo con } 4 \\
\text { artejos }\end{array}$ \\
\hline Tercer maxilípedo & Exópodo con 3 artejos; endópodo con 6 artejos & $\begin{array}{l}\text { Exópodo con } 2 \text { artejos reducidos; } \\
\text { endópodo con } 5 \text { artejos }\end{array}$ \\
\hline Telson & 11 setas plumosas & 10 setas plumosas \\
\hline Relación de setas de Urópodos & Exópodo con 9 y endópodo con 10 & Exópodo con 16 y endópodo con 7 \\
\hline
\end{tabular}

P. cummingi y P. paludosus, la morfología larval es muy similar y la principal diferencia es la talla de sus larvas (Dobkin, 1971).

\section{Agradecimientos}

Gabino A. Rodríguez -Almaráz agradece al Fondo Sectorial SEMARNAT-CONACYT por apoyar económicamente este estudio a través del proyecto 2002COI-0583, "Biosistemática y estado actual de la distribución ecológica-geográfica de los crustáceos decápodos de agua dulce del noreste de México y norte de Veracruz". También se recibió apoyo complementario del Programa de Apoyo a la Investigación Científica y Tecnológica de la Universidad Autónoma de Nuevo León, durante 20042007. Rodolfo Muñiz-Martínez recibió una beca del CONACYT para realizar sus estudios de doctorado en la Facultad de Ciencias Biológicas, Universidad Autónoma de Nuevo León. Alejandro Millán-Cervantes recibió una beca para concluir su tesis de licenciatura por parte de los Fondos Sectoriales SEMARNAT-CONACYT (Proyecto 0583).

\section{Literatura citada}

Álvarez, F., J. L. Villalobos y R. Robles. 2002. Abbreviated larval development of Macrobrachium tuxtlaense Villalobos and Álvarez, 1999, reared in the laboratory. Crustaceana
75:717-730.

Anderson, G. 1985. Species profiles: life histories and environmental requirements of coastal fishes and invertebrates (Gulf of Mexico) - Grass shrimp. U.S. Fish and Wildlife Service, Biological Report 82 (11.35) U.S. Army Corps of Engineers, TR EL-82-4, 19 p.

Beck, J. T. y B. C. Cowell. 1976. Life history and ecology of the freshwater caridean shrimp, Palaemonetes paludosus (Gibbes). American Midland Naturalist 96:52-65.

Broad, A. C. 1957. Larval development of Palaemonetes pugio Holthuis. Biological Bulletin 112 :144-161.

Broad, A. C. y J. H. Hubschman. 1963. The larval development of Palaemonetes kadiakensis M. J. Rathbun in the laboratory. Transactions of the American Microscopical Society 82:185197.

Cheper, N. J. 1992. Palaemonetes kadiakensis (Crustacea: Decapoda) in Oklahoma, 1982 and 1987. Proceedings of the Oklahoma Academy of Science 72:65.

Corey, S. y D. M. Reid. 1991. Comparative fecundity of decapods crustacean I. The fecundity of thirty three species of nine families of caridean shrimps. Crustaceana 60:270-294.

Dobkin, S. 1963. The larval development of Palaemonetes paludosus (Gibbes, 1850) (Decapoda, Palemonidae), reared in the laboratory. Crustaceana 6:41-61.

Dobkin, S. 1971. The larval development of Palaemonetes cummingi Chace, 1954 (Decapoda, Palaemonidae), reared in the laboratory. Crustaceana 20:285-297.

Falciai, L. y E. Palmerini. 2002. Larval development of the freshwater shrimp, Palaemonetes antennarius $(\mathrm{H}$. Milne Edwards, 1837) (Decapoda, Palaemonidae) reared in the laboratory. Crustaceana 74:1315-1333.

Guerao, G. 1993. The larval development of freshwater prawns, Palaemonetes zariquieyi Sollaud, 1939 (Decapoda, 
Palaemonidae) reared in the laboratory. Crustaceana 64:226241.

Hendrickx, M. E. 1995. Camarones In Guía FAO para la identificación de especies para fines de la pesca. Pacífico Centro-Oriental. I. Plantas e invertebrados, W. Fischer, F. Krumpp, W. Schneider, C. Sommer, K.E. Carpenter y V. H. Niem (eds.). FAO, Roma. p. 415-537 .

Holthuis, L. B. 1952. The subfamily Palaemoninae, part II: a general revision of the Palaemonidae (Crustacea: Decapoda: Natantia) of the Americas. Allan Hancock Foundation Occasional Papers 12:396.

Jalihal, D. R., K. N. Sankolli y S. Shenoy. 1993. Evolution of larval development patterns and the process of freshwaterization in the prawn genus Macrobrachium Bate, 1868 (Decapoda, Palaemonidae). Crustaceana 65:365-376.

Jayachandran, K. V. 2001. Palaemonid prawns: biodiversity, taxonomy, biology and management. Science, Enfield, New Hampshire, $624 \mathrm{p}$.

Lowe, B. T. y A. J. Provenzano. 1990. Survival and reproduction of Palaemonetes paludosus (Gibbes, 1850) (Decapoda, Palaemonidae) in saline water. Journal of Crustacean Biology 10:639-647.

Magalhães, C. e I. Walker. 1988. Larval development and ecological distribution of central Amazonian palaemonid shrimps (Decapoda: Caridea). Crustaceana 55:279-292.

Meehan, O. L. 1936. Notes on the freshwater shrimp Palaemonetes paludosa (Gibbes). Transactions of the American Microscopical Society 55:433-441.

Nazari, E. V., M. Rauh Müller y D. Ammar. 2000. Embryonic development of Palaemonetes argentinus Nobili, 1901 (Decapoda, Palaemonidae), reared in the laboratory. Crustaceana 73:143-152.

Pereira, G. A. y J. V. García.1995. Larval development of Macrobrachium reyesi Pereira (Decapoda: Palaemonidae), with a discussion on the origin of abbreviated development in palaemonids. Journal of Crustacean Biology 15:117-133.

Reinsel, K. A., P. S. Glas, J. R. Rayburn, M. K. Pritchard y W. S. Fisher. 2001. Effects of food availability on survival, growth, and reproduction of the grass shrimp Palaemonetes pugio: a laboratory study. Marine Ecology Progress Series 220:231239.

Rodríguez-Almaraz, G. A., J. A. González-Aguilar y R. Mendoza-Alfaro. 1997. Biological and ecological notes of Palaemonetes suttkusi (Crustacea: Palaemonidae) from Cuatro Cienegas basin, Coahuila, México. The Southwestern Naturalist 42:501-503.

Rodríguez-Almaraz, G. A. y R. Muñiz-Martínez. 2008. Conocimiento de los acociles y langostinos del noreste de México: amenazas y propuestas de conservación. In Crustáceos de México: estado actual de su conocimiento, F. Álvarez y G. A. Rodríguez-Almaraz (eds.). Dirección de Publicaciones, Universidad Autónoma de Nuevo León, Monterrey p. 167-206.

Rodríguez F., F. J. Barroso y M. D. Galindo. 1993. Estudio biométrico y morfológico de los huevos de Palaemonetes varians Leach de dos localidades del suroeste español. Limnetica 9:67-72.

Sollaud, E. 1923. Le développement larvaire des Palaemoninae. Bulletin Biologique de la France et de la Belgique 57:509603.

Strenth, N. E. 1976. A review of the systematics and zoogeography of the freshwater species of Palaemonetes Heller of North America (Crustacea: Decapoda). Smithsonian Contributions to Zoology 228:1-28.

Strenth, N. E.1991. The significance of the larval development of Palaemonetes antrorum Benedict (Crustacea: Decapoda) on the origin of subterranean palaemonids. Stygologia 6:149153.

Strenth, N. E. 1994. A new species of Palaemonetes (Crustacea: Decapoda: Palaemonidae) from northeastern Mexico. Proceedings of the Biological Society of Washington 107:291-295.

Strenth, N. E., J. D. Norton y G. Longley. 1988. The larval development of the subterranean shrimp Palaemonetes antrorum Benedict (Decapoda, Palaemonidae) from central Texas. Stygologia 4:363-370.

Welsh, B. L. 1975. The role of grass shrimp, Palaemonetes pugio, in a coastal marsh ecosystem. Ecology 56:513-530. 